\title{
Exploiting KRAS-driven Ferroaddiction in Cancer Through Ferrous Iron-Activatable Drug Conjugates (FeADC)
}

Honglin Jiang ${ }^{1,6}$, Ryan K. Muir ${ }^{2}$, Ryan L. Gonciarz ${ }^{2}$, Adam B. Olshen ${ }^{3,6}$, Iwei Yeh ${ }^{4,6}$, Byron C. Hann $^{6}$, Ning Zhao ${ }^{5}$, Yung-hua Wang ${ }^{5}$, Spencer C. Behr ${ }^{5}$, James E. Korkola ${ }^{7}$, Michael J. Evans ${ }^{5,6}$, Eric A. Collisson ${ }^{1,6}$, Adam R. Renslo ${ }^{2,6}$

1. Department of Medicine, University of California, San Francisco, San Francisco, California 94158, United States

2. Department of Pharmaceutical Chemistry, University of California, San Francisco, San Francisco, California 94158, United States

3. Department of Epidemiology and Biostatistics, University of California, San Francisco, San Francisco, California 94158, United States

4. Departments of Pathology and Dermatology, University of California, San Francisco, San Francisco, California 94158, United States

5. Department of Radiology and Biomedical Imaging, University of California, San Francisco, San Francisco, California 94158, United States

6. Helen Diller Family Comprehensive Cancer Center, University of California, San Francisco, San Francisco, California 94158, United States

7. Center for Spatial Systems Biomedicine, Oregon Health \& Sciences University, Portland, OR 97201, United States

Correspondence: eric.collisson@ucsf.edu, adam.renslo@ucsf.edu

Lead Contact: eric.collisson@ucsf.edu

Key words: Pancreatic ductal adenocarcinoma, Lung adenocarcinoma, Iron metabolism, MAPK Pathway 


\section{Summary}

KRAS mutations cause a quarter of cancer mortality and currently are not sensitive to any targeted, FDA-approved agents. Several inhibitors of the MAPK pathway are FDA approved but exhibit low clinical tolerability at doses needed to adequately extinguish KRAS signaling. We discovered an avidity for ferrous iron $\left(\mathrm{Fe}^{2+}\right)$ induced by and dependent on oncogenic KRAS signaling. We leveraged an FDA-approved MEK inhibitor to produce a prototypical Ferrous Iron-Activatable Drug Conjugate (FeADC) and with this novel agent achieved MAPK blockade in tumor cells while sparing normal tissues. These improvements allowed sustainable, effective treatment of tumor bearing animals with superior tolerability. Iron-activated therapeutics are unknown outside of antiparasitic therapy but may hold significant promise for the treatment of KRAS-driven solid tumors.

\section{Introduction}

The uptake, transport, and storage of iron is tightly controlled in biology but often dysregulated in cancer. Transcriptional profiling has suggested a link between elevated iron levels and poor prognosis in in gliomas (Han et al., 2018), breast (Torti and Torti, 2013a) and prostate cancers (Tesfay et al., 2015), but clinical studies based on iron chelation have proved disappointing (Buss et al., 2003). New insights into iron homeostasis have been revealed through genome-wide association studies (GWAS) and the recent development of iron probes with oxidation-state specificity. In a very recent GWAS study of lysosome function (Weber et al., 2020), it was shown that unloading of iron from transferrin and delivery of bioavailable ferrous iron $\left(\mathrm{Fe}^{2+}\right)$ to the cell was the single indispensable function of lysosomal acidity for cell proliferation. This remarkable finding was presaged by studies of the bacterium $P$. aeruginosa, where genetic deletion of a bacterioferrireductase (limiting cytosolic $\mathrm{Fe}^{2+}$ ) produced acute iron starvation despite more than adequate $\mathrm{Fe}^{3+}$ bacterioferritin stores (Eshelman et al., 2017). Elevation of cytosolic $\mathrm{Fe}^{2+}$ may enable the survival of TKI-tolerant 'persister' cancer cells (Hangauer et al., 2017), which become uniquely reliant on the activity of GPX4, a lipid hydroperoxidase that protects from ferroptosis (Dixon and Stockwell, 2014; Stockwell et al., 2017). Taken together, these studies suggest that access to bioavailable $\mathrm{Fe}^{2+}$ (as opposed to total iron) is a key to cancer cell survival. The mechanisms by which oncogene-mediated transformation lead to such 'ferroaddiction' remain unknown. 
Pancreatic ductal adenocarcinoma (PDA) is among the most aggressive and lethal solid tumors with a 5-year survival rate of $\sim 9 \%$ (Siegel et al., 2018). Systemic therapies are only marginally successful and no targeted therapies against genomic aberrations exist in this disease. Oncogenic KRAS mutation is a hallmark feature of PDA. While constitutive RAS/MAPK pathway activation drives uncontrolled proliferation and enhances survival of cancer cells, it also sensitizes tumor cells to ferroptosis (Dixon et al., 2012). Here we explore the elevation of intracellular $\mathrm{Fe}^{2+}$ in KRAS-driven tumor cells in vitro and in vivo, and target these tumors with a prototypical Ferrous Iron-Activatable Drug Conjugate (FeADC) that ablates MAPK signaling in tumor while sparing tissues that are dependent on normal RAS/MAPK signaling.

\section{Results}

\section{A Ferrous Iron Signature is Prognostic in Pancreatic Adenocarcinoma}

To explore the role of iron metabolism in cancer, we evaluated mRNA transcriptional data from 23 tumor types profiled by TCGA with a focus on Iron homeostatic programs using biological pathway activity (BPA) method (UCSC Xena). The cancer types with the highest Z-scores were all RAS-MAPK pathway-driven malignancies including: Glioblastoma Multiforme (GBM), Lung Adenocarcinoma (LUAD) and pancreatic ductal adenocarcinoma (PAAD) (Figure 1A). STEAP3 (a lysosomal ferrireductase) and TFRC (transferrin receptor) encode key genes in iron homeostasis. We compared mRNA levels of the STEAP3 and TFRC genes to overall patient survival (OS) in PAAD, a disease with the highest rates of KRAS mutations. Both STEAP3 and TFRC expression were both associated with shorter OS by Cox regression (Figure 1B). Liver metastasis is a uniformly poor prognostic sign in PDA. We examined STEAP3 expression in an independent primary and metastatic PDA dataset (Aguirre et al., 2018) and found STEAP3 expression to be higher in liver metastases than in all other metastatic sites $(p=0.0001$, Figure 1C). Gallium-68 citrate is a clinically studied radiotracer that mimics $\mathrm{Fe}^{3+}$-loaded on transferrin and is used to study iron demand in cancer patients (Behr et al., 2018; Larson et al., 1980). To assess iron avidity in PDA, we conducted an exploratory human imaging study with Ga-68 citrate positron emission tomography (PET). Quantitative analysis of the imaging data showed that visceral and bony PDA metastases were highly avid for Gallium-68 compared to normal tissues

\section{Figure 1D.}

To better understand these clinical observations, we sought to explore $\mathrm{Fe}^{3+}$ and $\mathrm{Fe}^{2+}$ avidity in xenograft mouse models. We observed enhanced uptake of Gallium-68 in mutant KRAS $\left(K R A S^{m}\right)$ 
driven PDA xenografts as compared to breast cancer xenografts with wt KRAS (Figure 1E). To assess levels of reduced iron in the same tumors, we used ${ }^{18} \mathrm{~F}-\mathrm{TRX}$, our recently described (Muir et al., 2019) oxidation-state specific radiotracer for $\mathrm{Fe}^{2+}$. We found that the mKRAS-driven PDA tumors were enriched in $\mathrm{Fe}^{2+}$ as compared to the wt KRAS tumors, mirroring our findings with ${ }^{68} \mathrm{Ga}$ (Figure S1A). Together these findings suggest that increased iron uptake and iron reduction are common in PDA and associated with poor patient prognosis. 
Figure 1
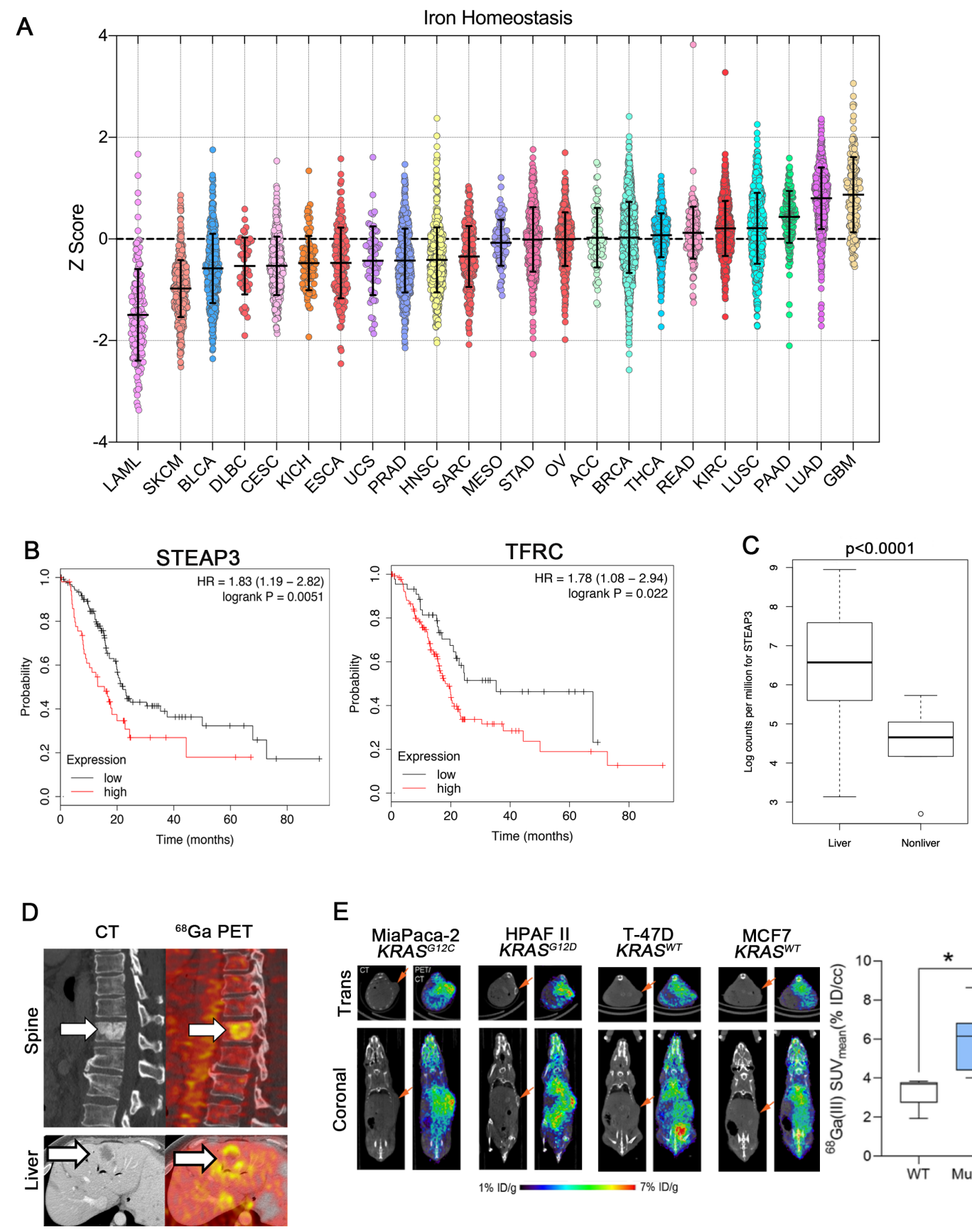

E

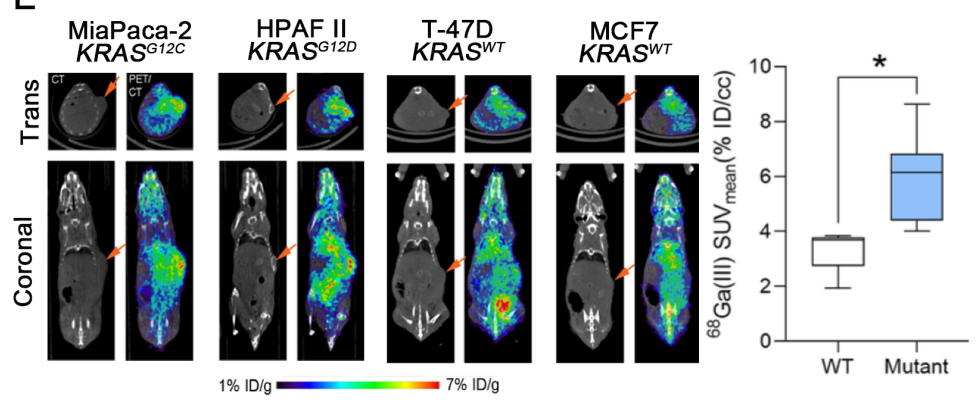

Figure1 A ferrous iron signature is prognostic in pancreatic adenocarcinoma

A. Pan Cancer analysis of Iron Homeostasis. Z-sores are plotted for each of 23 tumor types. Medians for each tumor type are ranked from lowest to highest $(R \rightarrow L)$. Error bars represent mean $\pm S E M$.

B. PAAD patients were binarized into high (upper half) or low (lower half) of mRNA expression of STEAP3 and TFRC. Survival in months was estimated by the method of Kaplan and Meir. HR= Hazard Ration for Overall Survival.

C. Boxplot showing the Median expression of STEAP3 in liver vs. non-liver-based sites of PAAD patients. 
D. Representative CT(Left) and fused $\mathrm{Ga}^{68}$ citrate PET/CT (Right) images demonstrating Ga ${ }^{68}$ citrate avid metastases within the T10 vertebral body and liver from two patients with pancreatic ductal adenocarcinoma.

E. Representative $\mathrm{Ga}^{68} \mathrm{PET}$ images of mice bearing xenografts with wild type or mutant KRAS. Tumors bearing an oncogenic KRAS mutation have an increased avidity for $\mathrm{Ga}^{68}$. Error bars represent mean \pm SEM, $n=3$ mice/group and analyzed by two sample t test. ${ }^{*} p<0.05$.

\section{Oncogenic KRAS Drives an Accumulation of Labile Ferrous Iron}

We next investigated the mechanism(s) by which oncogenic KRAS drives elevations in intracellular $\mathrm{Fe}^{2+}$. To control $K R A S^{G 12 D}$ expression in a time-dependent manner, we isolated primary skin fibroblasts from a Lox-Stop-Lox KRAS (LSL-KRAS $\left.{ }^{G 12 D}\right)$ conditional model, in which the expression of $K R A S^{G 12 D}$ is controlled by removal of a Cre recombinase-sensitive transcriptional Stop element. Removal of the Stop element from the $L S L-K R A S^{G 12 D}$ allele was achieved by the use of an adenovirus expressing Cre recombinase (AdenoCre). Primary skin fibroblasts were harvested at $24 \mathrm{hr}, 48 \mathrm{hr}$ and $72 \mathrm{hr}$ after AdenoCre infection. We observed robust expression of KRAS as well an increase in MAPK signaling, as demonstrated by phospho-ERK induction (Figure 2A). Intracellular labile $\mathrm{Fe}^{2+}$ also increased, as measured with the $\mathrm{Fe}^{2+}$-selective florescent dye SiRhoNox (Hirayama et al., 2019), (Figure 2B). KRAS ${ }^{G 12 D}$ expression in these primary cells also slowed proliferation and increased $\mathrm{p} 21^{\mathrm{CIP}}$ level as observed by others (Serrano et al., 1997) (Supplementary Figure S1B-C). Similarly, increased intracellular ferrous iron was observed in both HPDE cells (immortalized human pancreatic duct epithelial cells) and HBEC cells (immortalized human bronchial epithelial cells) after expression of KRAS ${ }^{G 12 D}$ by lentiviral transduction (Figure 2C-D). Evaluation of a larger panel of human malignant cell lines from PDA and breast cancer confirmed that cells harboring mutant KRAS had higher levels of total intracellular iron (Figure 2E). These results demonstrate early and sustained increases in $\mathrm{Fe}^{2+}$ as a consistent effect of oncogenic KRAS expression and distinctly uncouple $\mathrm{Fe}^{2+}$ accumulation from cellular proliferation in primary cells which undergo and $\mathrm{Fe}^{2+}$-rich replicative arrest upon acute exposure to high levels of KRAS ${ }^{\mathrm{G} 12 \mathrm{D}}$.

To further elucidate the effect of oncogenic KRAS on iron metabolism and transportation, we used an engineered mouse PDA cell lines in which the expression of $K \mathrm{ras}^{G 12 D}$ is under doxycycline control (designated $i$ Kras $^{G 12 D}$ ) (Ying et al., 2012). Extinction of Kras protein and phospho-ERK occurred within 48hr following doxycycline withdrawal (Figure 2F). Upon Kras ${ }^{G 12 D}$ ablation, three iKras lines, AK38, AK196 and AK210, exhibited significant decreases in Steap3 expression and elevation of Fpn (Ferroportin, an iron exporter) expression (Figure 2G). We further confirmed 
oncogenic Kras activation resulted in similar regulatory effects on the expression of STEAP3 and FPN in three normal cell lines HPDE, AALE and MEFs (Figure S1D). These data suggest that oncogenic KRAS is necessary and sufficient to maintain an elevated ferrous iron pool, at least in part by increased expression of ferrireductase and reduced iron efflux.

Figure 2

A

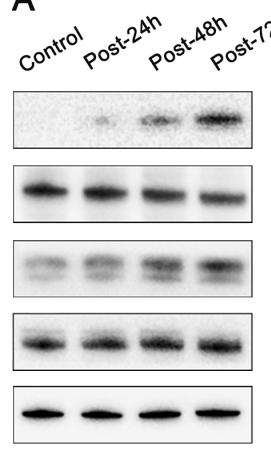

C

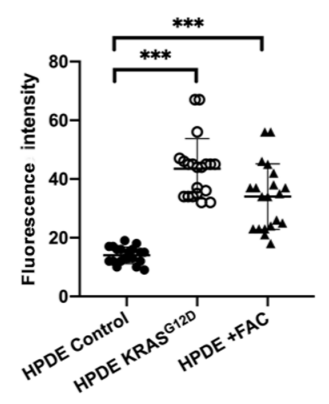

$\mathrm{F}$

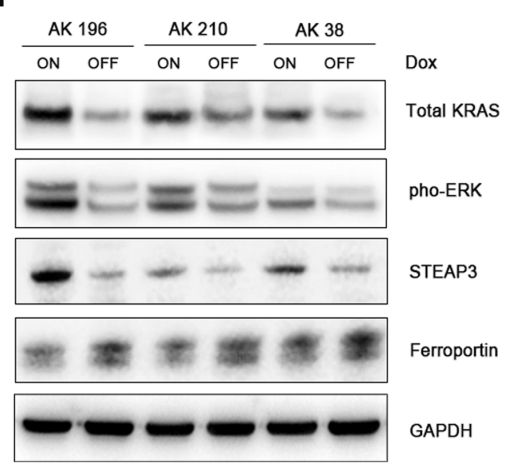

B
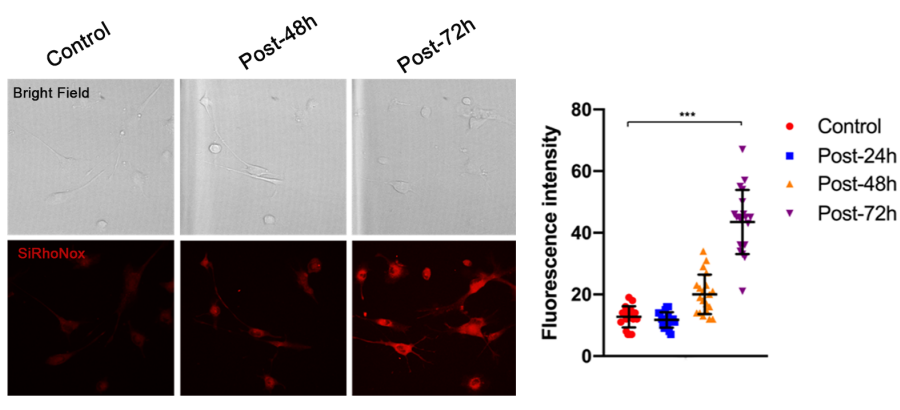

G
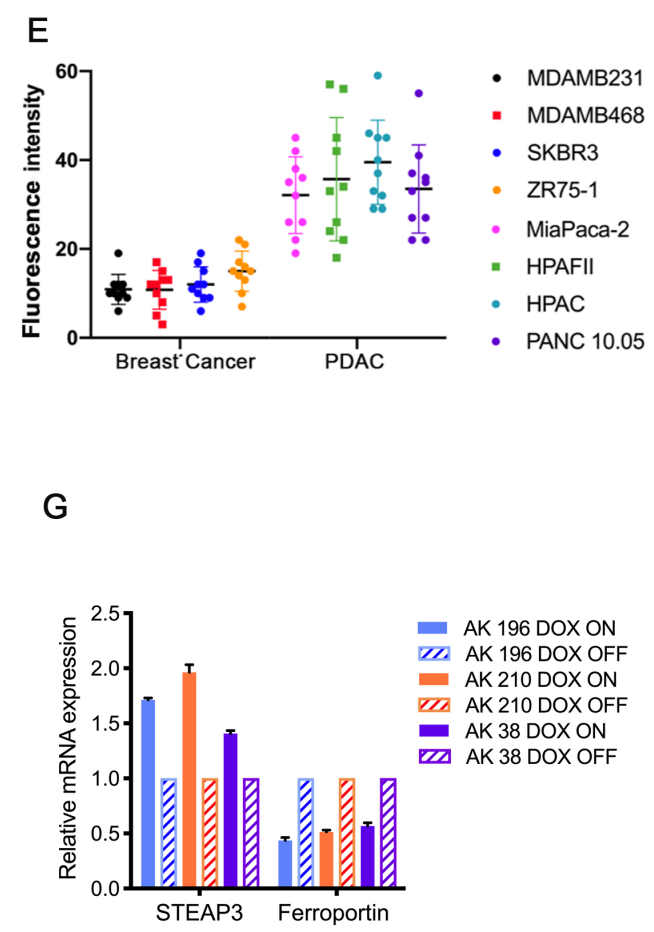

Figure2 Oncogenic KRAS drives an accumulation of labile ferrous iron

A. Western blot for KRAS ${ }^{\mathrm{G} 12 \mathrm{D}}$, KRAS, phosphorylated ERK and total ERK in LSL-KRAS ${ }^{\mathrm{G} 12 D}$ mouse fibroblasts after treatment with AdenoCre at $24 \mathrm{~h}, 48 \mathrm{~h}$ and $72 \mathrm{~h}$.

B. Representative images of bright field and IF staining for SiRhoNox in $L S L-K R A S^{G 12 D}$ mouse fibroblasts before and after the treatment with AdenoCre at $48 \mathrm{~h}$ and $72 \mathrm{~h}$. Quantifications of the fluorescence intensity per cell are plotted. 
C. Quantifications of the fluorescence intensity stained with SiRhoNox in HPDE, HPDE KRAS ${ }^{\text {G12D }}$ cells and HPDE cells treated with ferric ammonium citrate (FAC).

D. Quantifications of the fluorescence intensity stained with SiRhoNox in HBEC, HBEC KRAS ${ }^{G 12 D}$ cells and HBEC cells treated with ferric ammonium citrate (FAC).

E. Quantifications of the fluorescence intensity stained with SiRhoNox in various breast and pancreatic cancer cell lines.

F. Western blot for KRAS ${ }^{\mathrm{G} 12 \mathrm{D}}$, KRAS, phosphorylated ERK and total ERK in iKRAS cells treated with or without doxycycline.

G. Quantative PCR analysis of STEAP3 and Ferroportin in iKRAS cells treated with or without doxycycline. Error bars represent mean \pm SEM, $n=10$ cells/group in $B, n=20$ cells/group in $C-E$ and $n=3$ replicates in $G$, and analyzed by two sample t test. ${ }^{* *} p<0.01,{ }^{* * *} p<0.001$.

\section{Ferrous Iron-Activatable Drug Conjugate (FeADC) Targets Elevated Ferrous Iron in PDA}

$K R A S$ is the most commonly mutated oncogene in human cancer but has proven difficult to target pharmacologically. RAF-MEK-MAPK is the major effector arm in PDA (Collisson et al., 2012) and other RAS-driven malignancies including myeloid leukemia (Burgess et al., 2017) and lung cancer (Karreth et al., 2011). Since we found elevated labile $\mathrm{Fe}^{2+}$ to be driven by oncogenic KRAS, we hypothesized that KRAS-driven PDA tumor cells might be selectively targeted with a Ferrous Iron-Activatable Drug Conjugate (FeADC) based on 1,2,4-trioxolane (TRX) chemistry (Fontaine et al., 2014). Clinical precedent for $\mathrm{Fe}^{2+}$-dependent pharmacology is found in the established antimalarial artemisinin, but this novel mode of drug action has remained essentially unexplored outside of anti-protozoal therapies. To determine whether an FeADC might be effective in PDA, we probed PDA cells with an $\mathrm{Fe}^{2+}$-activatable conjugate of the aminonucleoside puromycin (TRXPURO(Spangler et al., 2016). Puromycin is released from the TRX-PURO FeADC in cells via reaction with $\mathrm{Fe}^{2+}$ (Figure $3 \mathrm{~A}$ ), the degree of release can be quantified with $\alpha$-puromycin antisera. We applied TRX-PURO to the same fibroblasts harboring a cre-inducible $K R A S^{G 12 D}$ allele under the ROSA26 locus to acutely and synchronously induce high levels of oncogenic KRAS ${ }^{G 12 D}$. We observed a time-dependent increase in puromycin signal out to $72 \mathrm{hr}$ post-infection (Figure $3 \mathrm{C}$ ), mirroring our findings with SiRhoNox (Figure 2B), and indicating the efficient $\mathrm{Fe}^{2+}$-dependent activation of TRX-PURO in cells expressing oncogenic KRAS.

Having established that mKRAS elevates intracellular $\mathrm{Fe}^{2+}$ as measured with both SiRhoNox and TRX-PURO, we sought to inhibit the RAF-MEK-ERK pathway in PDA with a new FeADC based on TRX chemistry. Targeting MEK with allosteric inhibitors of MEK1/2 has shown clinical benefit but also dramatic, on-target toxicities that are dose limiting in the eye, skin and other organs. Clinical experience has shown sustainable dosing of these agents is typically only $\sim 25 \%$ of the FDA-approved dose (Saunders et al., 2020) severely hampering the dose intensity achievable in the tumor cell. To model MEK inhibitor toxicity in animals, we administered the MEK inhibitor 
binimetinib for three weeks to healthy mice. We observed thinning of the epidermal keratinocyte layer in tail skin (Figure S2A). We hypothesized that a FeADC targeting MEK would be efficiently activated by $\mathrm{Fe}^{2+}$ in mKRAS tumors, but not in healthily mouse epidermis, where normal iron homeostasis is intact. We covalently linked the FDA-approved MEK inhibitor cobimetinib (COBI) to both enantiomeric forms of the TRX moiety to produce novel FeADCs $(R, R)-\mathrm{TRX}-\mathrm{COBI}$ and $(S, S)$-TRX-COBI (Figure 3B). Incubation of these FeADCs in mouse and human liver microsomes revealed somewhat superior metabolic stability of $(R, R)$-TRX-COBI (Supporting Information) and so this form was used in all additional studies (henceforth denoted simply TRX$\mathrm{COBI}$ ). We next evaluated the pharmacokinetic properties of TRX-COBI in NSG mice following a single $15 \mathrm{mg} / \mathrm{kg}$ dose by the IP route. We observed a favorable exposure profile, with an elimination half-life of $\sim 6.9 \mathrm{hrs}, \mathrm{C}_{\max }=1421 \mathrm{ng} / \mathrm{mL}$, and $\mathrm{AUC}_{\text {inf }}=6462 \mathrm{~h}^{*} \mathrm{ng} / \mathrm{mL}$ (full parameters provided in Supplementary Information). Significantly, the extent of free COBI released from TRX-COBI in this study was minimal, ca. $\sim 2 \%$ of the total dose by $\mathrm{C}_{\max }$ and $\mathrm{AUC}_{\text {inf. }}$ Overall, the pharmacokinetic properties of TRX-COBI were similar to that reported previously for $\mathrm{COBI}$ in $\mathrm{Nu} / \mathrm{Nu}$ mice (Choo et al., 2012), suggesting TRX-COBI as a suitable FeADC prototype for in vivo study.

We compared the growth inhibitory effects of TRX-COBI and COBI across a panel of human PDA cells harboring mKRAS and found that TRX-COBI was efficiently activated, as evidenced by similar phospho-ERK reductions at comparable (equimolar) exposure levels of COBI (Figure 3D). We further explored the efficiency of TRX deconjugation across a panel of cancer cell lines with known KRAS mutational status. We measured the growth inhibitory dose $\left(\mathrm{GI}_{50}\right)$ of TRX-COBI and $\mathrm{COBI}$ for each cell line to generate a TRX susceptibility ratio (i.e. $\mathrm{GI}_{50} \mathrm{COBI} / \mathrm{GI}_{50} \mathrm{TRX}-\mathrm{COBI}$ ). PDA cells all exhibited higher susceptibility $\left(\mathrm{Gl}_{50}\right.$ ratios) than breast cancer cell lines (Figure 3E), indicating efficient activation of FeADCs is a general feature of KRAS-driven PDA cells. Finally, depletion of STEAP3 in MiaPaca2 and Capan1 cells led to decreased concentrations of intracellular $\mathrm{Fe}^{2+}$ (Figure S2B) and, as expected, engendered resistance to TRX-COBI as measured by phospho-ERK/ERK ratios (Figure S2C-D). Together these data indicated that a prototypical FeADC is effective in mKRAS-driven PDA cells and that activation depends on the cellular ferroreductive machinery shown above to be under control of oncogenic KRAS. 


\section{Figure 3}

\section{A}

$\mathrm{Fe}(\mathrm{II})$-Activatable Drug Conjugate (FeADC)

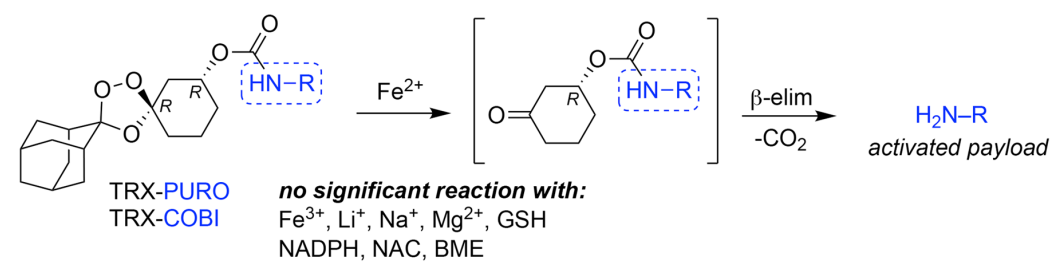

B

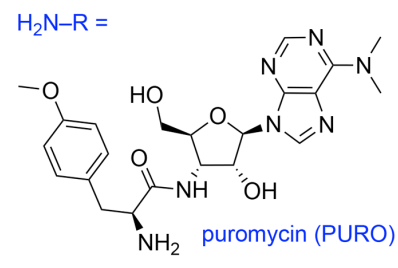

C

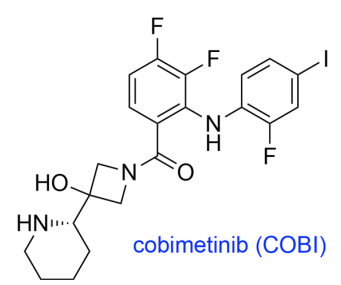

Normalized TRX-PURO Signal

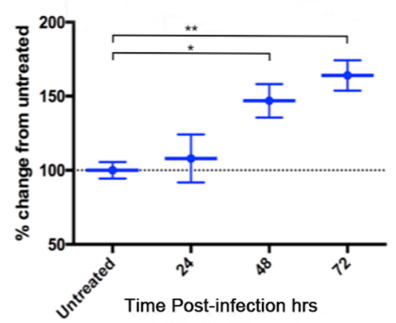

E

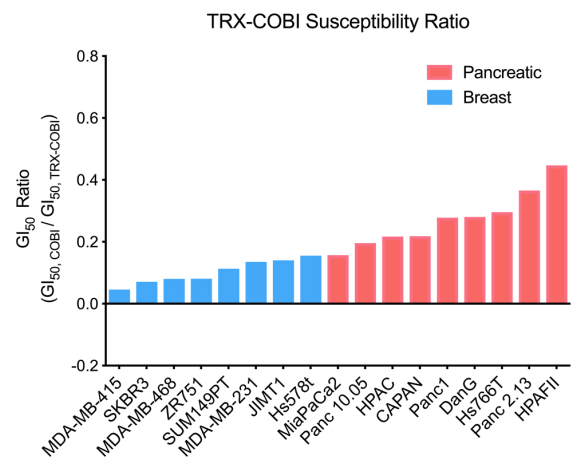

Figure3 Ferrous Iron-Activatable Drug Conjugate (FeADC) targets elevated ferrous iron in PDA

A. Structure and mechanism of FeADC activation by ferrous iron sources.

B. Chemical structure of FeADC payloads puromycin and cobimetinib (COBI).

C. Normalized TRX-PURO signals in $L S L-K R A S^{G 12 D}$ mouse fibroblasts before and after the treatment with AdenoCre at $24 \mathrm{~h}, 48 \mathrm{~h}$ and $72 \mathrm{~h}$.

D. Western blot for phosphorylated ERK in COBI or TRX-COBI treated MIAPaca-2, HPAFII and PANC 02.03 cells at indicated doses.

E. A panel or breast and pancreatic cancer cells were dosed with $\mathrm{COBI}$ and TRX-COBI for 72 hours. The $\mathrm{Gl}_{50}$ of TRX-COBI for each cell was normalized to that of parent COBI to generate a TRX susceptibility ratio. 


\section{An FeADC of Cobimetinib Exhibits Potent Anti-Tumor Activity in vivo}

We next evaluated the FeADC approach to MEK1/2 inhibition in vivo. We orthotopically implanted

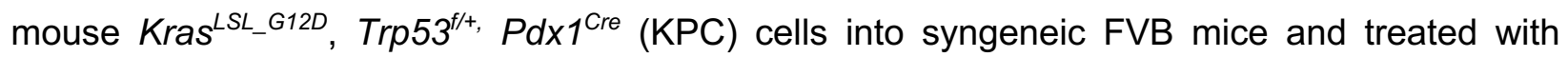
equimolar doses of either TRX-COBI or COBI. Both $\mathrm{COBI}$ and TRX-COBI caused comparable tumor growth inhibition (Figure 4A-B) and showed equivalent suppression of phospho-ERK in this orthotopic PDA model (Figure 4G-H). We next evaluated the effects of COBI and TRX-COBI on overall survival in an autochthonous Kras ${ }^{L S L-G 12 D /+}$; Trp53 flox/flox, $(K P)$ mouse lung cancer model (Jackson et al., 2001). We initiated treatment with equimolar doses of COBI, TRX-COBI or vehicle 8 weeks after the adenoviral induction for 60 days. Mice receiving either COBI or TRX-COBI (equimolar doses) had fewer lung lesions (as evidenced by LSL-Tomato florescence) and showed prolonged overall survival compared to vehicle treated mice (Figure 4C-D). We further examined the therapeutic efficacy of TRX-COBI in patient-derived xenograft (PDX) models. Two KRAS ${ }^{G 12 D_{-}}$ driven PDA patient derived xenograft (PDX) models and a $K R A S^{G 12 C}$-driven non-small cell lung cancer (NSCLC) PDX. Both $\mathrm{COBI}$ and TRX-COBI each significantly inhibited tumor growth relative to vehicle-treated tumors (Figure 4E-F). In addition, tumor lysates as well as tumor histology from the PDX PDA260 confirmed that TRX-COBI reduced pERK as effectively as parental did COBI (Figure 4G-H). Collectively, these data demonstrate equivalent in vivo antitumor activity at equimolar doses of TRX-COBI or $\mathrm{COBI}$ in multiple relevant KRAS-driven models in vivo. 
Figure 4

A
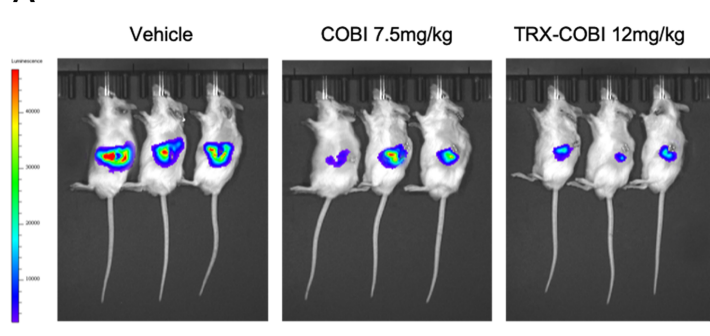

C
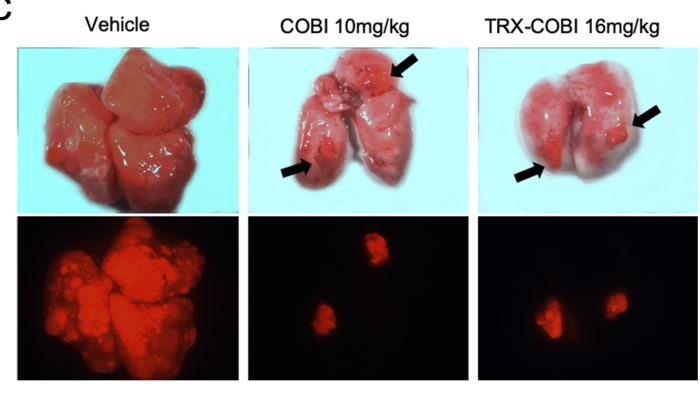

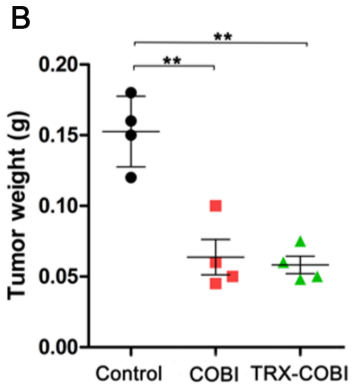

D

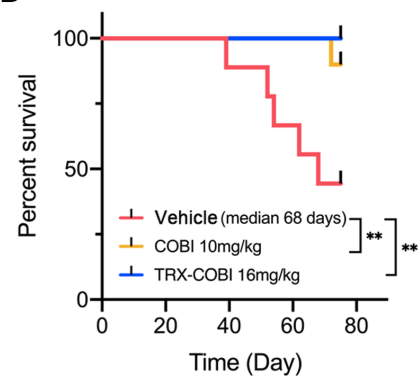

E

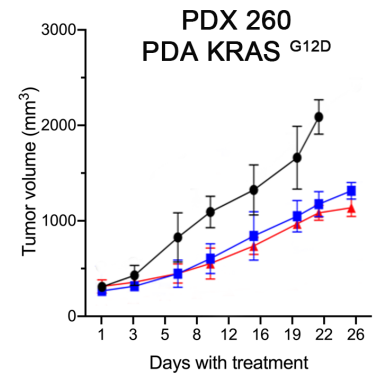

G

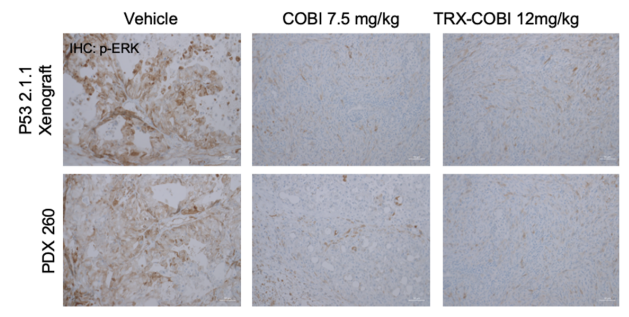

F

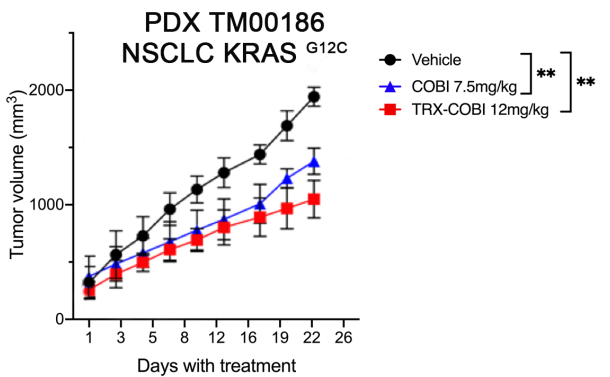

H

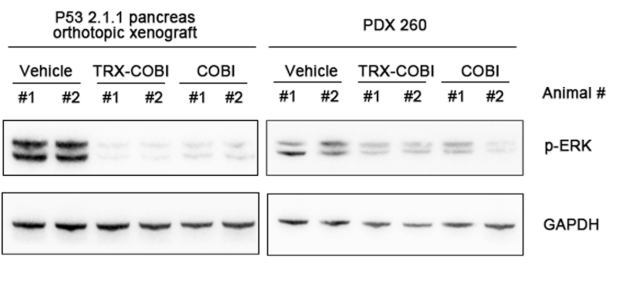

Figure 4 An FeADC of Cobimetinib exhibits potent anti-tumor activity in vivo

A. Representative bioluminescence images for the effects of vehicle and the equimolar dose of COBI and TRX-COBI on p53 2.1.1-fLuc orthotopic pancreas tumor xenografts.

B. Tumor weights at the end point from A. Error bars represent mean \pm SEM, $n=4-5$ mice/group and analyzed by two-sample t-test. ${ }^{* *} p<0.01$.

C. Representative gross lung images in KP mouse model. Vehicle, equimolar dose of COBI and TRXCOBI treatment started 8 weeks after the adenoviral induction and continued for 60 days.

D. Overall survival of (C) analyzed by logrank test, $n=8-10$ mice/group, ${ }^{* *} p<0.01$.

E-F. Tumor volume changes (mean \pm SEM; error bars) of KRAS mutant PDA and NSCLC PDX model, $n=8-10$ mice/group. Data were analyzed by one-way ANOVA ** $p<0.01$.

G. IHC of xenografts from A and $E(10 X)$ stained with phosphorylated ERK.

$H$. Western blot for phosphorylated ERK of tumors resected at the end of treatment in $A$ and $E$. 


\section{FeADC Approach Mitigates MEK Inhibitor On-Target Off-Tumor Toxicities}

We next asked whether the FeADC approach could mitigate on-target, off-tissue toxicities of systemic MEK inhibition, reasoning that TRX-COBI should remain inactive (caged) in the normal tissues (skin, retina) that are negatively impacted by systemic MEK inhibition in cancer patients. We used retinal cells and keratinocytes as experimentally tractable models of two known tissues of MEK inhibitor toxicity. We found that human retinal pigment epithelia cells (RPE-1) and human keratinocytes (HaCaT) were about 10-fold less sensitive than PDA cells to TRX-COBI, as evidenced by intact pERK levels, in the off-target cells at drug concentrations sufficient to completely abolish pERK in PDA cells. In stark contrast, parental COBI more potently inhibited MEK1/2 in the keratinocytes than in PDA cells (Figure 5A). These results suggest that the FeADC approach can achieve improved therapeutic index in mKRAS-driven cancers at the cellular level of end organ toxicity.

Next, we explored the tissue-selective activation of FeADCs in animals. We administered a single, equimolar dose of either TRX-COBI, COBI or vehicle to PDA tumor-bearing NSG mice, followed $6 \mathrm{hrs}$ later by collection of plasma and harvesting of tissue samples from brain, liver, spleen, tail skin, and orthotopic tumor. We observed equivalent exposure of COBI and TRX-COBI by the IP route and very limited free form of $\mathrm{COBI}$ in the plasma of TRX-COBI treated mice (Figure 5B). We observed decreases in pERK was tumor, but also in each of the above stated "off-target" tissues in COBI-treated animals. We found tumor pERK was abolished to an equivalent level as with TRX-COBI as in COBI-treated mice, while pERK was maintained (similar to vehicle control) in brain, spleen, liver, and tail skin (Figure 5C and Figure S3A). This suggested that TRX-COBI remained caged in normal tissues while still extinguishing KRAS signaling in tumors of the same mice. To model the cumulative toxicities of chronic, systemic MEK inhibition, we collected tail skin samples from mice dosed with equimolar amounts of TRX-COBI, COBI or vehicle for 20 days and measured the cellular epidermal layer. We found a reduction of the epidermal layer only in mice dosed with COBI (Figure 5D). Together, these findings show that many of the MEK1/2dependent (on target) extra-tumoral toxicities (Scholl et al., 2009),(Balagula et al., 2011) of MEK inhibition are substantially mitigated through the FeADC approach, which shows promise to improve the poor therapeutic index of RAS-RAF-MAPK blockade in the clinic. 
Figure 5

A
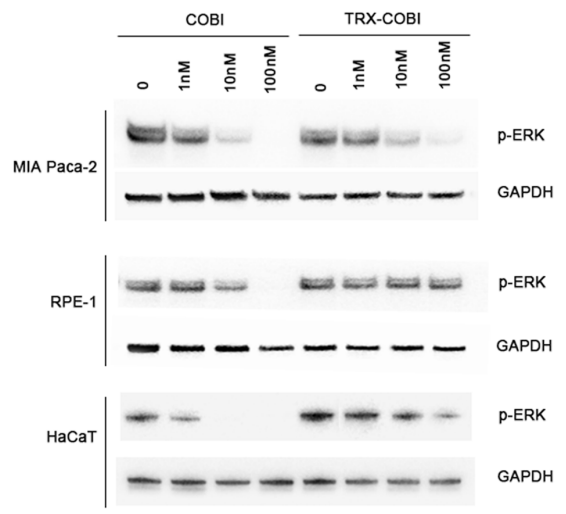

C
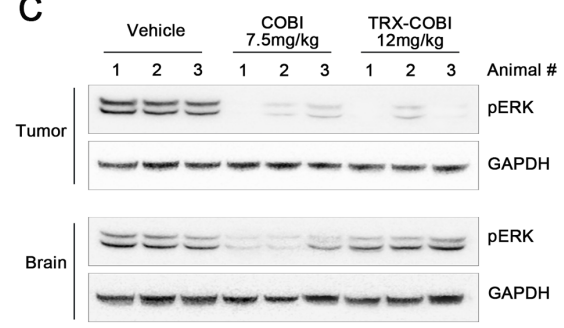

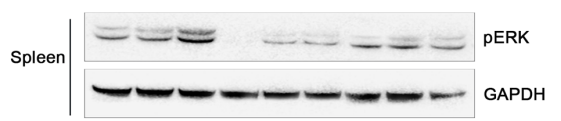

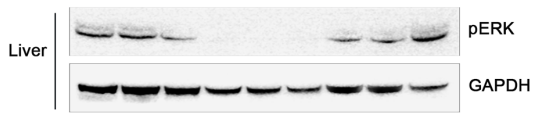

B

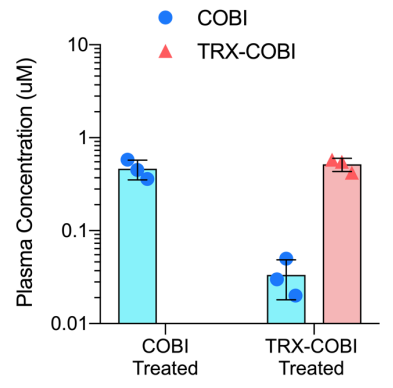

D

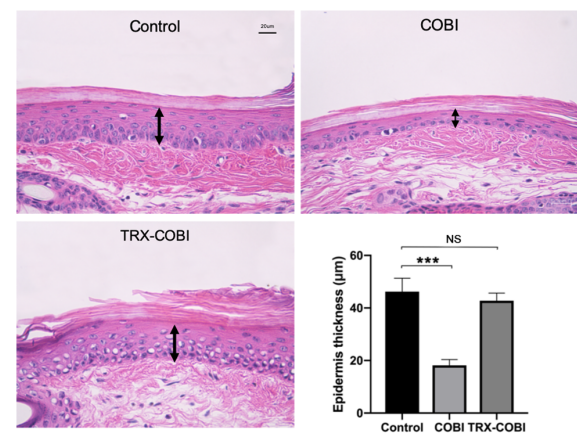

Figure 5 A FeADC approach mitigates MEK inhibitor On-Target / Off-Tumor toxicities

A. Western blot for phosphorylated ERK of MiaPaca2, RPE-1 and HaCaT cells treated with $\mathrm{COBI}$ and TRX-COBI at indicated dose.

B. Plasma concentration of $\mathrm{COBI}$ and TRX-COBI after treatment for 8h. Data was determined by LCMS/MS assay. Error bars represent mean \pm SEM.

C. Western blot for phosphorylated ERK of tumor xenografts, brain, spleen and liver from NSG mice after treatment with vehicle, the equimolar dose of $\mathrm{COBI}$ and TRX-COBI for $8 \mathrm{~h}$.

D. Representative images of $\mathrm{HE}(40 \mathrm{X})$ show the epidermal layer of mouse tail skin after the treatment with vehicle, the equimolar dose of $\mathrm{COBI}$ and TRX-COBI for 20days. Error bars represent mean $\pm \mathrm{SEM}$, $\mathrm{n}=3$ mice/group and analyzed by two sample t test. ${ }^{* *} \mathrm{p}<0.001$. 


\section{MEK Inhibition with FeADC Enables Dose Intensity in Combination Therapies}

The inherently low therapeutic index of MEK inhibitors has hindered development of combination therapy. Our encouraging data with TRX-COBI monotherapy augured for improved tolerance of combination treatment schemes anchored in MEK inhibition combined with inhibition of other RAS effectors or activators. Inhibition of SHP2 can sensitize many cycling dependent KRAS-mutant or KRAS-amplified cancers to MEK inhibitors (Ruess et al., 2018). While such vertical blockade holds tremendous promise, combination therapy of SHP2 and MEK inhibitors negatively effects tolerability in mice (Fedele et al., 2018). Indeed, we found the combination of Cobimetinib and the SHP2 inhibitor SHP099 (Novartis) induced study-terminating body weight loss from baseline within three weeks in non-tumor bearing NSG mice (Figure S3B).

To assess the potential of FeADC strategies to improve the toxicity profile of vertical MAPK pathway blockade, we first assessed cytotoxicity of combined MEK+SHP2 dual inhibition in PDA (MiaPaca2) vs. normal (RPE-1 and HaCaT) cells. Treatment of non-malignant RPE-1 and HaCaT cells with increasing concentrations of COBI enhanced cell growth inhibition of SHP2 inhibitor (SHP099, 10uM) while equimolar combinations of TRX-COBI/SHP2 were less toxic to these normal cells (Figure 6A-B). In contrast, MiaPaca-2 cells showed equivalent sensitivity to the two combinations (Figure 6C), indicating a potentially improved safety profile with and comparable efficacy of TRX-COBI in MEK inhibitor-based combination therapies.

We next compared the efficacy and tolerability of TRX-COBI to $\mathrm{COBI}$ when combined with the SHP2 inhibitor RMC-4550 (Revolution Medicines) in KRAS ${ }^{G 12 C}$ NSCLC (TM00186) PDX model. Six separate groups of mice were administered vehicle, $30 \mathrm{mg} / \mathrm{kg}$ RMC-4550 monotherapy, or combinations comprising $30 \mathrm{mg} / \mathrm{kg}$ of RMC-4550 combined with COBI at either $7.5 \mathrm{mg} / \mathrm{kg}$ or 10 $\mathrm{mg} / \mathrm{kg}$, or RMC-4550 with comparable (equimolar) $12.5 \mathrm{mg} / \mathrm{kg}$ or $16 \mathrm{mg} / \mathrm{kg}$ doses of TRX-COBI. Of note, mice receiving the combination of $\mathrm{COBI} 10 \mathrm{mg} / \mathrm{kg}$ plus RMC $30 \mathrm{mg} / \mathrm{kg}$ lost weight ( 10\%) (Figure 6A) and exhibited lassitude. Remarkably, the equivalent combination of TRX-COBI 16 $\mathrm{mg} / \mathrm{kg}$ with RMC $30 \mathrm{mg} / \mathrm{kg}$ induced the most pronounced tumor growth inhibition without weight loss (Figure 6B), indicating that FeADC-based MEK inhibition combined with SHP2 blockade exhibits superior tolerability and improved efficacy in KRAS driven tumors. 
Figure 6
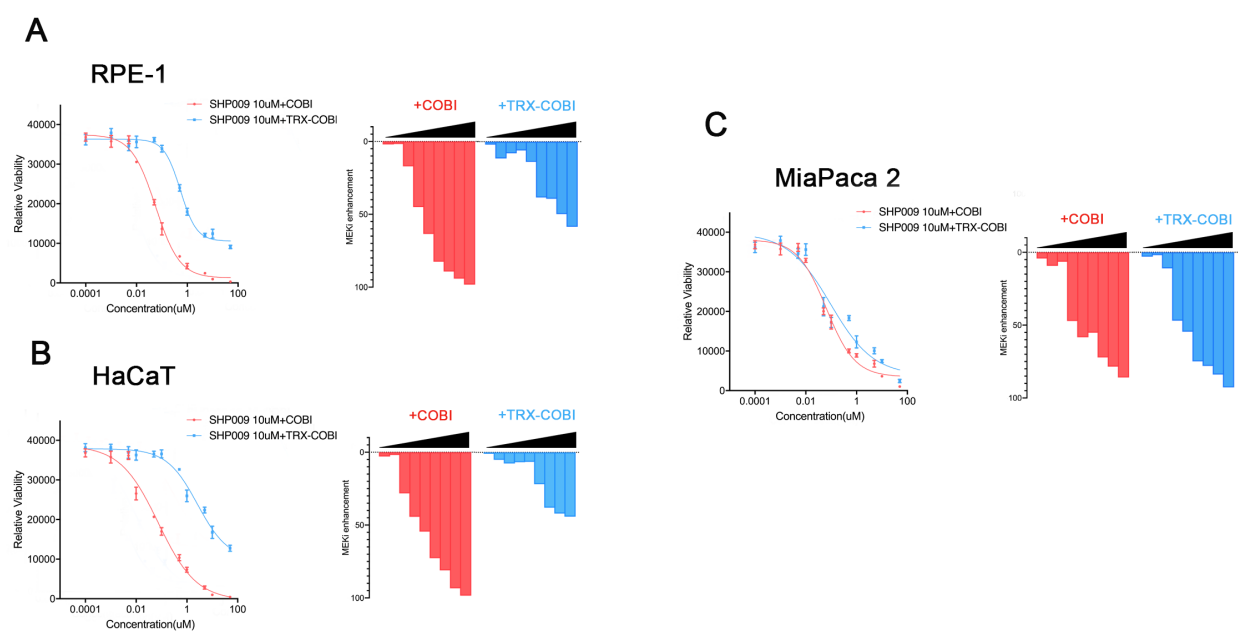

D

PDX TM00186

$E$
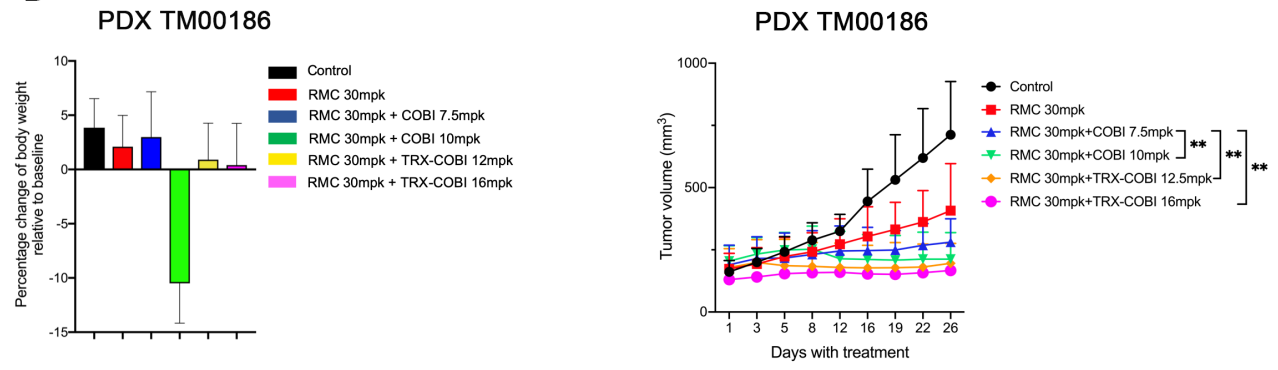

Figure 6 MEK inhibition with FeADC enables dose intensity in combination therapies

(A-C) RPE-1, HaCaT and MiaPaca2 cells were treated with increasing concentrations of COBI or TRX$\mathrm{COBI}$ in the presence of $10 \mathrm{uM} \mathrm{SHP009}$ for 72 hours, and viability was determined. The enhancement of growth inhibition by the addition of COBI or TRX-COBI to SHP009 was determined by normalizing the viability after combination treatment to SHP009 for each dose point $(0=$ no effect; $100 \%=$ complete cell killing).

(D) Mouse body weight changes normalized to the baseline after the treatment of vehicle, $30 \mathrm{mg} / \mathrm{kg} \mathrm{RMC-}$ 4550 monotherapy, or combinations comprising $30 \mathrm{mg} / \mathrm{kg}$ of RMC-4550 combined with COBI at either 7.5 $\mathrm{mg} / \mathrm{kg}$ or $10 \mathrm{mg} / \mathrm{kg}$, or RMC-4550 with comparable (equimolar) $12.5 \mathrm{mg} / \mathrm{kg}$ or $16 \mathrm{mg} / \mathrm{kg}$ doses of TRXCOBI. Error bars represent mean \pm SEM, $n=6$ mice/group.

(E) Tumor volume changes of PDX TM00186 tumors after the treatments in D. Error bars represent mean \pm SEM, $n=6$ mice/group and analyzed by one-way ANOVA ** $p<0.01$. 


\section{Discussion:}

Iron, as an enzyme cofactor, powers energy production and macromolecule synthesis essential for cell proliferation and survival. Here we confirm an iron-avid phenotype in PDA consistent with observations in breast cancer (Miller et al., 2011; Pinnix et al., 2010), prostate cancer (Tesfay et al., 2015), and glioblastoma (Schonberg et al., 2015),. More specifically, we show that an elevated pool of $\mathrm{Fe}^{2+}$ iron characterizes PDA and other KRAS driven malignancies. Ferroaddiction comes at a cost however (Dixon et al., 2012), since labile $\mathrm{Fe}^{2+}$ promotes intracellular Fenton chemistry, in turn resulting in elevated intracellular reactive oxygen species (ROS) (Dizdaroglu and Jaruga, 2012; Inoue and Kawanishi, 1987) and ferroptosis-associated lipid peroxidation that in turn engenders dependence on ROS-detoxifying enzymes like GPX4 (Forcina and Dixon, 2019; Liu et al., 2018) and FSP1 (Bersuker et al., 2019; Doll et al., 2019). Our studies in KRAS-driven cells and tumors directly link oncogenic KRAS to elevated $\mathrm{Fe}^{2+}$ and a vulnerability to ferroptosis (Dixon et al., 2012).

Iron homeostasis is tightly controlled at the level of the cell and organism and the dysregulation of iron regulatory genes in cancer biology has been recognized for some time (Torti and Torti, 2013b). How specific oncogenes drive iron utilization to sustain tumor growth remains unclear. Crucially, the study of iron with oxidation-state specificity has been impossible prior to the recent advent of chemical probes that can distinguish ferrous from ferric states. Here we show that KRAS signaling is necessary and sufficient to drive $\mathrm{Fe}^{2+}$ demand and production in PDA cells. Oncogenic KRAS in particular exerts control over key iron transporters, exporters, and lysosomal ferrireduction, which collectively serve to maintain an expanded pool of bioavailable $\mathrm{Fe}^{2+}$. Ras oncogenes have been shown to alter nutrient metabolism (Hensley et al., 2016; Perera and Bardeesy, 2015; Ying et al., 2012), and here we provide evidence that oncogenic KRAS signaling also alters iron oxidative metabolism in favor of $\mathrm{Fe}^{2+}$ during tumor development and maintenance.

Most KRAS-mutant cancers depend on sustained expression and signaling of KRAS, thus making it a high-priority therapeutic target (Papke and Der, 2017; Stephen et al., 2014). Unfortunately, development of direct small molecule inhibitors of KRAS function has been challenging. Moreover, single-agent inhibition of KRAS effectors (e.g. MEK-MAPK pathway) in KRAS-mutant cancers have been disappointing to date (Adjei et al., 2008; Infante et al., 2012; Ko et al., 2016; Zhao and Adjei, 2014). On-target MEK inhibition in healthy tissues dramatically limits the tolerable dose and also the feasibility of MEK inhibitor-based combination therapy. The cellular pathways influenced 
by dominant acting oncogenes are often essential for homeostatic maintenance of healthy tissues in patients. As a result, potent inhibitors of pathways downstream of mutated oncogenes often have deleterious effects in healthy tissues. This manifests as clinical toxicity. Furthermore, since pathway flux is often greater in cancer cells than in normal cells, the amount of inhibitor required for therapeutic efficacy in the tumor often closely approaches or even exceeds the dose tolerable clinically by healthy tissues.

The iron(II)-mediated Fenton reaction underlies the pharmacology of artemisinins and related endoperoxide antimalarials (Ansari et al., 2013; O'Neill and Posner, 2004). Leveraging this clinically proven chemistry (Fontaine et al., 2014; Mahajan et al., 2012), we introduced the concept of the Ferrous Iron-Activatable Drug Conjugate (FeADC). Having uncovered in the current study an elevation of $\mathrm{Fe}^{2+}$ stemming from oncogenic KRAS/MAPK signaling, we synthesized and evaluated TRX-COBI, a novel FeADC designed to target the MAPK pathway in KRAS-driven PDA. We demonstrate ablation of MAPK signaling with TRX-COBI in KmKRASdriven PDA and lung tumor cells and xenografts, with sparing of the pathway in normal cells and tissues, notably including in major organs of iron storage (liver) and in the skin cells that are a site of clinically relevant on-target toxicity of current MEK inhibitors. These findings are significant in that they reveal a targetable pool of $\mathrm{Fe}^{2+}$ in mKRAS-driven cancers, decouple MAPK signaling from elevated $\mathrm{Fe}^{2+}$ status in normal and tumor cells, and present a therapeutic strategy that exploits these distinctions to enable more tolerable and efficacious combination therapy targeting the MAPK pathway in mKRAS-driven malignancies. 


\section{Acknowledgments}

We thank Bob Nichols, Mallika Singh and Trever Bivona for their scientific advice and comments and the Shorenstein and Rombauer Families. We also thank PTC and LCA cores at UCSF Helen Diller Comprehensive Cancer Center. This work was supported by $\mathrm{NIH}, \mathrm{NCl}$ Grants R01 [CA178015, CA222862, CA227807, CA239604, CA230263], U24 [CA210974], U54 [CA224081] grants (EAC). NIH P30CA082103 (ABO). NIH Al105106 and Congressionally Directed Medical Research Program [W81XWH1810763 and W81XWH1810754] grants (ARR). American Cancer Society Research Scholar Grant (130635-RSG-17-005-01-CCE) (MJE). Content does not reflect the views of the Department of Defense, American Cancer Society, National Cancer Institute or National Institutes of Health.

\section{Authors Contributions}

Conception and design: H.J, E.A.C, A.R.R.

Development of methodology: H.J, R.K.M, E.A.C, A.R.R.

Data Acquisition: H.J, R.K.M, R.L.G, J.E.K, E.A.C, A.R.R.

Analysis and interpretation of data: H.J, R.K.M, R.L.G, A.B.O, I.Y, B.C.H, N.Z, Y.W, S.C.B, M.J.E, E.A.C, A.R.R

Writing and review of the manuscript: H.J, E.A.C, A.R.R

Study supervision: E.A.C, A.R.R.

\section{Declaration of Interests}

E.A. Collisson is consultant at Takeda, Merck, Loxo and Pear Diagnostics, reports receiving commercial research grants from Astra Zeneca, Ferro Therapeutics, Senti Biosciences, Merck $\mathrm{KgA}$ and Bayer and stock ownership of Tatara Therapeutics, Clara Health, BloodQ, Guardant Health, Illumina, Pacific Biosciences and Exact Biosciences. A.R. Renslo is consultant at Theras, Inc., and Elgia Therapeutics and reports stock ownership in Elgia Therapeutics and Tatara Therapeutics. No potential conflicts of interest were disclosed by the other authors. 


\section{STAR METHODS}

\section{KEY RESOURCES TABLE}

\begin{tabular}{|c|c|c|}
\hline REAGENT or RESOURCE & SOURCE & IDENTIFIER \\
\hline \multicolumn{3}{|l|}{ Antibodies } \\
\hline KRAS G12D & Cell Signaling Technology & 14429 \\
\hline KRAS & Cell Signaling Technology & 53270 \\
\hline Phospho-Erk1/2 (Thr202/Tyr204) & Cell Signaling Technology & 4370 \\
\hline Erk1/2 & Cell Signaling Technology & 4696 \\
\hline GAPDH & Cell Signaling Technology & 5174 \\
\hline STEAP3 & Proteintech & 17186 \\
\hline Ferroportin & Novus Biologicals & NBP1-21502SS \\
\hline \multicolumn{3}{|l|}{ Biological Samples } \\
\hline Patient-derived xenografts (PDX) 260 & UCSF & $\mathrm{NA}$ \\
\hline Patient-derived xenografts (PDX) TM00186 & The Jackson Laboratory & TM00186 \\
\hline \multicolumn{3}{|l|}{ Chemicals, Peptides, and Recombinant Proteins } \\
\hline Cobimetinib & MedChemExpress & HY-13064 \\
\hline SHP099 & MedChemExpress & HY-100388 \\
\hline RMC-4550 & Revolution Medicine & NA \\
\hline SiRhoNox & GORYO Chemical & GC903-01 \\
\hline M-PER ${ }^{\mathrm{TM}}$ Protein Extraction Reagent & Thermo Scientific & 78501 \\
\hline Halt $^{\mathrm{TM}}$ protease and phosphatase inhibitor cocktail & Thermo Scientific & 78441 \\
\hline XenoLight D-Luciferin & PerkinEImer & 12799 \\
\hline Ga-68 citarte & UCSF radiopharmacy core & NA \\
\hline \multicolumn{3}{|l|}{ Critical Commercial Assays } \\
\hline Pierce $^{\mathrm{TM}}$ BCA Protein Assay Kit & Thermo Scientific & 23225 \\
\hline CellTiter-Glo Luminescent Cell Viability Assay & Promega & G7570 \\
\hline \multicolumn{3}{|l|}{ Experimental Models: Cell Lines } \\
\hline MiaPaca-2 & ATCC & CRL-1420 \\
\hline HPAF II & ATCC & CRL-1997 \\
\hline HPAC & ATCC & CRL-2119 \\
\hline Panc 10.05 & ATCC & CRL-2547 \\
\hline Panc 02.03 & ATCC & CRL-2553 \\
\hline Capan1 & S.K. Batra & NA \\
\hline MDAMB231 & M.M. Moasser & NA \\
\hline MDAMB468 & M.M. Moasser & NA \\
\hline ZR75-1 & M.M. Moasser & NA \\
\hline SKBR3 & M.M. Moasser & NA \\
\hline T47-D & M.M. Moasser & NA \\
\hline AK38, AK196 and AK210 & R Perera & NA \\
\hline$L S L-K R A S^{G 12 D}$ fibroblasts & Generated & NA \\
\hline p53 2.1.1 & Collisson et al., 2012 & NA \\
\hline
\end{tabular}




\begin{tabular}{|c|c|c|}
\hline Kras $^{L S L-G 12 D /+} ; \operatorname{Trp} 53^{\text {flox/flox }}$ & Jackson et al., 2001 & NA \\
\hline FVB/NJ & The Jackson Laboratory & 001800 \\
\hline NSG & The Jackson Laboratory & 005557 \\
\hline \multicolumn{3}{|l|}{ Software and Algorithms } \\
\hline Graphpad Prism 8 & GraphPad & https://graphpad.com \\
\hline $\mathrm{R}$ language & $\mathrm{R}$ language & http://www.r-project.org \\
\hline Advantage Windows Workstation & GE Health & GE Health \\
\hline ImageJ & $\mathrm{NIH}$ & $\mathrm{NIH}$ \\
\hline \multicolumn{3}{|l|}{ Other } \\
\hline Micro PET/CT scanner & Siemens Inveon & \\
\hline PET/CT scanner & Siemens AG & \\
\hline PET/MR scanner & GE Medical Systems & \\
\hline
\end{tabular}

\section{LEAD CONTACT AND MATERIALS AVAILABILITY}

Requests for additional information about the manuscript or for resources and reagents should be directed to and will be fulfilled by the Lead Contact, Eric Collisson (eric.collisson@ucsf.edu). All unique reagents generated in this study are available from the Lead Contact without restriction.

\section{EXPERIMENTAL MODEL AND SUBJECT DETAILS}

\section{Cell lines}

MiaPaca-2, HPAF II, HPAC, Panc 10.05 and Panc 02.03 are from American Type Culture Collection. Capan1 was provided by S.K. Batra (University of Nebraska, Lincoln, NE). MDAMB231, MDAMB468, ZR75-1, SKBR3 and T47-D were provided by M.M. Moasser (UCSF, CA). iKras lines AK38, AK196 and AK210 were provided by R Perera (UCSF, CA). Skin fibroblasts isolation from $L S L-K R A S^{G 12 D}$ mouse was performed as described (1). Cells were maintained at $37^{\circ} \mathrm{C}$ in a humidified incubator at $5 \% \mathrm{CO} 2$. Cells were grown in appropriate media as recommended by ATCC, and supplemented with $10 \%$ fetal bovine serum (Gibco) and $1 \%$ penicillin/streptomycin (Gibco). All cell lines tested were negative for mycoplasma contamination.

\section{Patient characteristics and accrual}

This study was approved by the UCSF Institutional Review Board (IRB) and was compliant with the Health Insurance Portability and Accountability Act. Informed consent was obtained from all patients enrolled into the study.

Patient inclusion criteria were (1) histologically confirmed/clinically suspected pancreatic cancer, (2) At least one lesion $\geq 1 \mathrm{~cm}$, (3) Age $>18$, (4) a signed informed consent indicating that they are 
aware of the investigational nature of this study, (5) negative for HIV, and (6) patients must not be pregnant or breast feeding.

Patient demographic information including age and sex were recorded as well as their tumor locations and histological grade.

\section{Mice models}

Small animal PET/CT and biodistribution studies: 6-week-old male NSG mice were purchased from Jackson lab.

Orthotopic pancreas xenografts. Derivation of the p53 2.1.1 FVB/n mice has been described (3).

KPT lung tumor model. Kras ${ }^{L S L-G 12 D /+} ; p 53^{\text {floxflox } ; R 26^{L S L-t d T o m a t o}}(K P T)$ mice have been previously described. Mice were bred on a mixed background.

PDXs. For generation of the PDX 260 model, informed consent was obtained from the patient as per an open IRB-approved protocol at the University of California, San Francisco. Tumors were implanted in NSG mice (Jackson Lab)

\section{METHOD DETAILS}

\section{Reagents and antibodies}

The following antibodies were used: KRAS G12D (Cell Signaling Technology, 14429, Dilution: 1:1000); KRAS (Cell Signaling Technology, 53270, Dilution: 1:1000); Phospho-Erk1/2 (Thr202/Tyr204) (Cell Signaling Technology, 4370, Dilution: 1:1000); Erk1/2 (Cell Signaling Technology, 4696, Dilution: 1:1000); GAPDH (Cell Signaling Technology, 5174, Dilution: 1:1000); STEAP3 (Proteintech, 17186, Dilution: 1:1000); Ferroportin (Novus Biologicals, NBP1-21502SS, Dilution: 1:1000). Cobimetinib and SHP099 were purchased from MedChemExpress. RMC-4550 was provided by Revolution Medicine.

\section{Image protocol}

Patients were injected with up to $15 \mathrm{mCi}(555 \mathrm{MBq}$ ) (average 7.42 $\mathrm{mCi}$ [274.6 MBq], range 3.7 to $11.9 \mathrm{mCi}$ [136.9 to $438.5 \mathrm{MBq}]{ }^{68} \mathrm{Ga}$-citrate intravenously. PET acquisition was acquired between 120 and 263 minutes after injection (average 210 minutes). Images were acquired on either a PET/CT or PET/MR. PET/CT examinations were performed on either a Biograph 16 (Hi-Rez) PET/CT scanner (Siemens AG, Erlangen, Germany) with an integrated PET and 16-MDCT scanner or a Discovery VCT PET/CT scanner (GE Medical Systems, Milwaukee, WI) with an 
integrated PET and 64-MDCT scanner. A low-dose CT was acquired for PET attenuation correction. PET/MR images were performed on a SIGNA PET/MR (GE Medical Systems, Milwaukee, $\mathrm{WI}$ ). Attenuation correction for PET reconstruction was performed using a MR-based attenuation correction (MRAC) technique provided by the scanner manufacturer.

\section{Image analysis}

Maximum intensity projection (MIP), axial, coronal and sagittal reconstructions and PET/MR fused images were reviewed on an Advantage Windows Workstation (AW, Waukesha, WI). PET images were evaluated by trained nuclear medicine physician blinded to the results of conventional imaging scans as well as clinical/genomic features of the case and scored for the presence of PET avid lesions. Lesions were considered PET positive if uptake was focal, greater than the adjacent background soft tissue and not in an expected physiologic structure such as the urinary bladder, vessels or salivary glands.

For semi-quantitative analysis, a volume of interest (VOI) was manually drawn around PET-avid lesions and SUV $\mathrm{V}_{\max }$ were recorded. The location of abnormal radiotracer uptake was compared

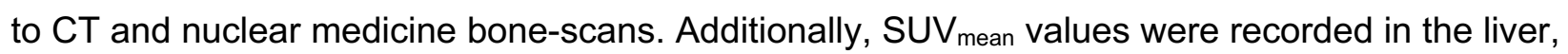
paraspinous soft tissues, bone (right sacrum), and mediastinal blood pool for determination of normal structures.

With conventional imaging, soft tissue metastases were considered positive if greater than $1 \mathrm{~cm}$ in long axis, except for lymph nodes that were considered positive if greater than $1.5 \mathrm{~cm}$ in short axis. Bone lesions on radionuclide scan were considered positive if uptake was focal and not in a pattern consistent with arthritis or antecedent trauma/fracture.

\section{Animal studies}

All experiments were approved by the IACUC of the University of California, San Francisco.

Small animal PET/CT and biodistribution studies: 6-week-old male NSG mice were purchased from Jackson lab. Mice were inoculated with $10^{7}$ cells subcutaneously into one flank in a 1:1 mixture (v/v) of media and Matrigel. Tumors were palpable within 20 days after transplantation. ${ }^{68} \mathrm{Ga}$-citrate was prepared by the Radiopharmacy core facility at UCSF as previously reported (2). 18F-TRX was prepared using the previously developed protocol. Radiotracers were administered via tail vein injection (150-250 $\mathrm{\mu Ci} /$ mouse). Imaging data were acquired 4 hours post injection of ${ }^{68} \mathrm{Ga}$-citrate, and $90 \mathrm{~min}$ post injection of ${ }^{18} \mathrm{~F}-\mathrm{TRX}$. The image acquisition was performed on the 
Siemens Inveon micro PET/CT under anesthesia by using $2.5 \%$ isoflurane at 4 hours post injection. The resulting imaging data was directly reconstructed, decay-corrected, and analyzed by AMIDE software, which was also used to place the region of interest (ROI) to calculate SUV data from the static acquisition. After the imaging data were collected, animals were euthanized by cervical dislocation. Tissues were removed, weighed and counted on a Hidex automatic gamma counter for accumulation activity. The mass of the injected radiotracer was measured and used to determine the total number of CPM by comparison with a standard of known activity. The data were background- and decay-corrected and expressed as the percentage of the injected dose/weight of the biospecimen in grams (\%ID/g).

Orthotopic pancreas xenografts. Derivation of the p53 2.1.1 FVB/n mice has been described (3). These cells were labelled in vitro with a lentiviral vector encoding a firefly luciferase to give rise p53 2.1.1syn_Luc. 1000 cells were orthotopically implanted in 6-week-old FVB/n mice in 20 $\mu \mathrm{L}$ composed 1:1 mixture (v/v) of media and Matrigel. Mice were treated with $7.5 \mathrm{mg} / \mathrm{kg}$ of COBI, $12 \mathrm{mg} / \mathrm{kg}$ TRX-COBI or vehicle control (saline) by daily IP for 3 weeks. Bioluminescent imaging was performed twice a week to monitor tumor growth.

KPT lung tumor model. Kras ${ }^{L S L-G 12 D /+} ; p 53^{\text {floxflox }} ; R 26^{L S L-t d T o m a t o}(K P T)$ mice have been previously described. Mice were bred on a mixed background. Adenovirus expressing Cre recombinase (Viraquest, University of lowa) were administrated intratracheally as previously described (4). Briefly, 2-3 months old mice were infected with $2 \times 10^{7}$ or $10^{8}$ pfu of adenovirus expressing Cre recombinase. After 40 days, $10 \mathrm{mg} / \mathrm{kg}$ of $\mathrm{COBI}, 16 \mathrm{mg} / \mathrm{kg}$ of TRX-COBI or vehicle control (saline) were dosed by IP five days a week for 6 weeks. Mice OS was analyzed and images of tumors expressing tdTomato were acquired with Zeiss Zeiss Axiolmager microscope.

PDXs. For generation of the PDX 260 model, informed consent was obtained from the patient as per an open IRB-approved protocol at the University of California, San Francisco. Tumors were implanted in NSG mice (Jackson Lab). TM00186 were obtained from Jackson laboratory. Both tumors were used at low passage for the experiments described herein. In figure 4, once tumors reached an average volume of $\sim 300 \mathrm{~mm}^{3}$, mice were treated with $7.5 \mathrm{mg} / \mathrm{kg}$ of COBI, $12 \mathrm{mg} / \mathrm{kg}$ TRX-COBI or vehicle control (saline) by daily IP for 25 days. In Figure 6, when tumors reached an average volume of $\sim 300 \mathrm{~mm}^{3}$, animals were randomized into six groups as indicated. RMC4550 was dosed by oral at $30 \mathrm{mg} / \mathrm{kg}$. Measurement of tumor volume and body weight were performed twice a week. 
TRX-COBI synthesis: The $(R, R)$ - and $(S, S)-$ TRX-COBI conjugates were prepared by coupling to known TRX intermediates via activated nitrophenyl carbonate as we have previously described (5) and as further detailed in the Supplemental Information.

\section{TRX-PURO assay}

Automated cell imaging was conducted using a GE IN Cell2000 automated cell imager. Graphing and analysis of data was done in GraphPad Prism 6. 3000 cells per well were plated in 96-well black $\mu$ Clear tissue culture plates (Greiner). The following day, cells were incubated with a mixture of growth medium and adeno-cre viral supernatant for 6 hours. Cells were then exposed to puromycin or TRX-PURO at $1 \mu \mathrm{M}$ (diluted in cell culture medium from 1,000× DMSO stocks) in medium for 24, 48 and 73 hours before medium was removed and cells were washed with PBS, fixed in 4\% PFA for 10 min at RT then washed twice with PBS and once with PBS containing $0.1 \%$ Triton X-100. Cells were then stained with Kerafast anti-puromycin antibody $(3 \mathrm{RH} 11,1: 500)$ in PBS with $10 \%$ FBS and $0.1 \%$ Triton X-100 for 30 min at $37^{\circ} \mathrm{C}$. Cells were washed once with PBS and once with PBS containing $0.1 \%$ Triton X-100 then stained with anti-mouse secondary FITC (488 nm excitation, $535 \mathrm{~nm}$ emission) antibody (1:100) and Hoechst nuclear stain at a final concentration of $10 \mu \mathrm{g} / \mathrm{mL}$ in PBS with $10 \%$ FBS and $0.1 \%$ Triton X-100 for $30 \mathrm{~min}$ at $37^{\circ} \mathrm{C}$. Cells were washed once with PBS containing $0.1 \%$ Triton X-100 and once with PBS then stored in PBS and imaged using an IN Cell 2000 automated cell imager at 10× magnification with 6-9 images per well in FITC and DAPI channel fluorescence. Images were analyzed for nuclei count and puromycin incorporation by IN Cell developer software. Puromycin incorporation was assessed by mean cellular fluorescence density in the FITC channel for each cell as defined by targets seeded with nuclei in the DAPI channel. Average cellular fluorescence density under each condition was determined, and reported values represent the mean average per well across triplicates \pm s.e.m. Signal in cells treated with the TRX-PURO was normalized to that in cells treated with free puromycin. These values were then normalized to untreated cells and reported at percent change from untreated.

\section{Cell Viability Assays}

3000-5000 cells optimized for each cell line were seeded on day 1, drug was added on day 2 (using DMSO normalized to $0.1 \%$ ), and the cell viability was determined using CellTiter-glo (Promega) on day 4. Viability curves were generated using GraphPad Prism 6. 


\section{Histological Analysis}

HE staining and immunohistochemistry were performed on 4- $\mu m$-thick sections of $4 \%$ paraformaldehyde-fixed and paraffin-embedded tissues. Tail sections were decalcified by incubation of trimmed paraffin blocks for 10-15 min on paper towels soaked in $1 \mathrm{~N} \mathrm{HCl}$. Epidermis thickness was measured by Zeiss Axiolmager microscope. Tumors sections were stained with phospho-p44/42 (Thr202/Tyr204, 9101, 1:50).

\section{Detection of Labile Ferrous Iron}

Cells were seeded and cultured overnight. Culture medium was removed on the following day rinse twice gently with PBS. A final concentration of $5 \mathrm{uM}$ of SiRhoNox (FerroFarRed, GORYO Chemical) in a serum-free culture medium was added to the dish and incubate for 1 hour at $37^{\circ} \mathrm{C}$. Fluorescence images were then acquired with Zeiss Spinning Disk Confocal microscope. Immunofluorescence was quantified using ImageJ software.

\section{Pharmacokinetic Assays}

NSG mice were administered a single IP dose of COBI $(7.5 \mathrm{mg} / \mathrm{kg}, \mathrm{n}=3)$ or TRX-COBI $(12 \mathrm{mg} / \mathrm{kg}$, $\mathrm{n}=3$ ). Blood was collected after 6 hours analyzed by Integrated Analytical Solutions, Inc (Berkeley, $\mathrm{CA})$.

\section{Western Blotting}

Tumor tissue and organ tissues was flash frozen in liquid nitrogen and homogenized in M-PER lysis buffer (Thermo Scientific) plus Halt ${ }^{\mathrm{TM}}$ protease and phosphatase inhibitor cocktail (Thermo Scientific). Protein concentrations were determined with the Pierce BCA Protein Assay Kit (Thermo Scientific), and extracts were loaded onto NuPAGE Bis-Tris SDS gels and immunoblots were visualized by LiCOR Odyssey system.

\section{STEAP3 knockdown}

For stable and lenti-virally transfected shRNA-based knockdown experiments, viruses were generated in HEK293T cells transfected with lentiviral packaging vectors along with vectors expressing pGIPZ-shSTEAP3 using Fugene6 (Promega). Two distinct hairpins were chosen for the experiments. Their sequences are as follows: STEAP3-1, 5'- TGAAGAACTTGTTCTGGCT; STEAP3-2, 5'- TGACCACTGTGCAAGTGGG-3'. Viral supernatant collected from confluent monoculture was filtered and used to infect MiaPaca-2 and Capan1 pancreatic cancer cells. A total of $0.5 \times 10^{6}$ cells was seeded in one well of a 6 -well chamber and allowed to grow for 
overnight. The following day, cells were incubated with a 1:2 mixture of growth medium and viral supernatant collected from HEK293T cells. Polybrene was added at $8 \mu \mathrm{g} \mathrm{ml} / \mathrm{l}$.

\section{QUANTIFICATION AND STATISTICAL ANALYSIS}

Statistical tests were performed using GraphPad Prism 7.0 or the R language. Two-sided twosample t-tests were used for comparisons of the means of data between two groups. One-way ANOVA was used for comparisons among multiple independent groups. The Cox proportional hazards model was used to asses OS, while the Kaplan-Meier method was used to visualize STEAP3 expression when stratified into high versus low. For animal studies, animals were randomized before treatments, and all animals treated were included for the analyses.

\section{References for Methods}

1. Khan $\mathrm{M}$ et al. Generating Primary Fibroblast Cultures from Mouse Ear and Tail Tissues. J Vis Exp. 2016 Jan 10;(107). doi: 10.3791/53565

2. Behr SC, et al. A feasibility study showing [68Ga] citrate PET detects prostate cancer. Mol Imaging Biol. 2016;18(6):946-951

3. Collisson EA et al. Subtypes of pancreatic ductal adenocarcinoma and their differing responses to therapy. Nat Med 2011;17:500-3

4. DuPage $\mathrm{M}$ et al. Conditional mouse lung cancer models using adenoviral or lentiviral delivery of Cre recombinase. Nat Protoc. 2009;4(7):1064-72

5. Blank B et al. Novel Antimalarial Trioxolanes with Superior Drug-Like Properties and Clinical Candidate Potential, ACS Infect. Dis. 2020, (Manuscript submitted). 


\section{Supplementary Information}

Exploiting KRAS-driven Ferroaddiction in Cancer Through Ferrous Iron-Activatable Drug Conjugates (FeADC)

\section{Table of Contents}

In Vitro ADME Data for (1"R,3"R) TRX-COBI and (1"S,3"S) TRX-COBI ..........2

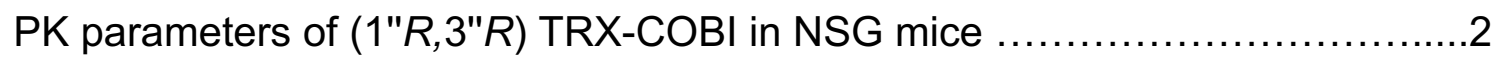

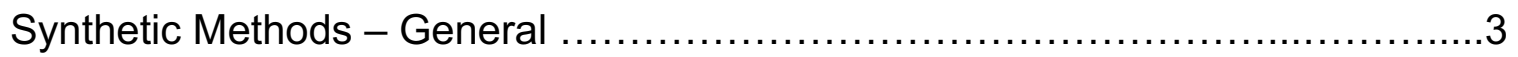

Preparation of $(R)$ - and $(S)$ - 4-nitrophenyl carbonate intermediates ................

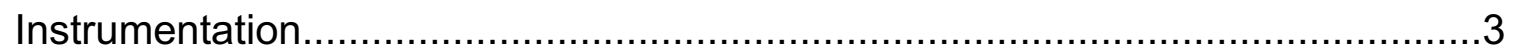

Synthetic Procedures for (1"R,3"R) TRX-COBI and (1"S,3"S) TRX-COBI .........5

Scans of NMR, HMRS Spectra and LC/MS Chromatograms............................9 
Table S1. Stability of (1"R, 3"R)-TRX-COBI and (1"S, 3"S)-TRX-COBI conjugates in Mouse Liver Microsomes (MLM) ${ }^{\mathrm{a}}$

\begin{tabular}{|c|c|c|c|c|c|c|c|c|c|}
\hline \multirow[t]{2}{*}{ Compound } & \multicolumn{3}{|c|}{ Slope } & \multicolumn{3}{|c|}{ MLM $T_{1 / 2}(\min )$} & \multicolumn{3}{|c|}{$\begin{array}{c}\mathrm{MLM} \mathrm{CL}_{\text {int }}^{\mathrm{c}} \\
(\mu \mathrm{L} / \mathrm{min} / \mathrm{mg} \\
\text { protein })\end{array}$} \\
\hline & $\mathrm{N}$ & \pm & SE & ean & \pm & SE & Mean & \pm & SE \\
\hline Ver & -0.1031 & \pm & $J e^{2}$ & & & .0 & 06.200 & \pm & 9.160 \\
\hline $\begin{array}{l}\text { (1"R,3"R)- } \\
\text { TRX-COBI }\end{array}$ & $\overline{-}-009773$ & \pm & 0.0002 & 70.9 & \pm & 2.1 & 19.546 & \pm & 0.570 \\
\hline $\begin{array}{l}\text { (1"S,3"S)- } \\
\text { TRX-COBI }\end{array}$ & .01273 & \pm & 0 & 54.4 & \pm & 11.6 & 25.460 & \pm & 5.434 \\
\hline
\end{tabular}

aStability of (1"R, 3"R)-TRX-COBI and (1"S, 3"S)-TRX-COBI at one concentration in mouse liver microsomes (MLM) at four time points $(T=0,15,30$, and $60 \mathrm{~min})$ and at $0.5 \mathrm{mg} / \mathrm{mL}$ protein concentration, $\mathrm{N}=1,+1 \mathrm{mM}$ NADPH. Percent of parent disappearance is monitored by LC/MS/MS. ${ }^{\text {bVerapamil served }}$ as a control. ${ }^{\circ}$ Clearance calculated as $(C L i n t)=\ln (2)^{*} 1000 / T_{1 / 2} /$ protein concentration, where protein concentration is in $\mathrm{mg} / \mathrm{mL}$. Metabolic stability assay performed by Quintara Discovery, Hayward, CA 94545.

Table S2. Pharmacokinetic parameters for (1"R, 3"R)-TRX-COBI and (released) COBI following a single $15 \mathrm{mg} / \mathrm{kg}$ IP dose of (1"R, 3"R)-TRX-COBI to NSG mice. ${ }^{a}$

\begin{tabular}{|c|c|c|c|c|c|}
\hline analyte & $\mathrm{T}_{\max }$ & $\mathrm{C}_{\max }$ & $\mathrm{T}_{1 / 2}$ & $\mathrm{AUC}_{\text {inf }}$ & MRT $_{\text {last }}$ \\
\hline $\mathrm{TRX}-\mathrm{COBI}$ & $0.08 \mathrm{~h}$ & $1421 \mathrm{ng} / \mathrm{mL}$ & $6.9 \mathrm{~h}$ & $6462 \mathrm{~h}^{*} \mathrm{ng} / \mathrm{mL}$ & $3.8 \mathrm{~h}$ \\
\hline $\mathrm{COBI}$ & $0.5 \mathrm{~h}$ & $17.4 \mathrm{ng} / \mathrm{mL}$ & $15.5 \mathrm{~h}$ & $276.9 \mathrm{~h}^{*} \mathrm{ng} / \mathrm{mL}$ & $4.3 \mathrm{~h}$ \\
\hline
\end{tabular}

aBioanalysis of plasma samples performed at Integrated Analytical Solutions, Berkeley, CA. 


\section{Synthetic Methods}

General All reactions were performed under an Argon atmosphere using anhydrous solvents obtained from commercial suppliers in oven-dried round-bottom flasks containing Teflon coated stirrer bars, unless otherwise noted. All anhydrous solvents used were purchased from Sigma-Aldrich and used without further purification. Solvents used during flash column chromatography and reaction work-up procedures were purchased from either Sigma-Aldrich or Fisher Scientific and were used without further purification. All other reagents were obtained commercially and used without further purification, unless otherwise stated. Air and/or moisture sensitive reagents were transferred via syringe and were introduced into reaction vessels through rubber septa. Reactions were monitored using thin layer chromatography (TLC), performed on 0.25 mm EMD pre-coated glass-backed silica gel 60 F-254 plates. Column chromatography was performed on Silicycle Sili-prep cartridges using a Biotage Isolera Four automated flash chromatography system. Compounds were visualized under UV light or through staining with permanganate, iodine, or most preferably for trioxolane analogs, Seebach's "Magic" stain (composed of the following: $2.5 \mathrm{~g}$ phosphomolybdic acid, $1.0 \mathrm{~g}$ cerium sulfate, $6 \mathrm{~mL}$ concentrated sulfuric acid, and $94 \mathrm{~mL}$ water). Solutions containing crude reaction mixtures, as well as those obtained upon reaction work-up, and chromatography fractions were first concentrated by rotary evaporation at temperatures under $40{ }^{\circ} \mathrm{C}$, at 20 Torr then subsequently placed under Hi-Vac at 0.5 Torr unless otherwise indicated. $(R)$ - and $(S)$ - 4-Nitrophenyl carbonate intermediates were prepared as reported previously ${ }^{1}$.

${ }^{1}$ Blank B et al. Novel Antimalarial Trioxolanes with Superior Drug-Like Properties and Clinical Candidate Potential, ACS Infect. Dis. 2020, (Manuscript submitted).

Instrumentation NMR spectra were recorded on a Bruker Avancelll HD $400 \mathrm{MHz}$ (with $5 \mathrm{~mm}$ BBFO Z-gradient Smart Probe), calibrated to $\mathrm{CH}(\mathrm{D}) \mathrm{Cl}_{3}$ as an internal reference (7.26 and 77.00 ppm for ${ }^{1} \mathrm{H}$ and ${ }^{13} \mathrm{C}$ NMR spectra, respectively). Data for ${ }^{1} \mathrm{H}$ NMR spectra are reported in terms of chemical shift $(\delta, \mathrm{ppm})$, multiplicity, coupling constant $(\mathrm{Hz})$, and integration. Data for ${ }^{13} \mathrm{C}$ NMR spectra are reported in terms of chemical shift $(\delta, \mathrm{ppm})$, with multiplicity and coupling constants in the case of $\mathrm{C}-\mathrm{F}$ coupling. The following 
abbreviations are used to denote the multiplicities: $\mathrm{s}=$ singlet; $\mathrm{d}=$ doublet; $\mathrm{t}=$ triplet; $\mathrm{q}=$ quartet; quin = quintet; sept $=$ septet; $m=$ multiplet. $a p p=$ apparent, or combinations of these. Where required, COSY, HSQC and HMBC were used for the assignment of protons and carbons. LC-MS and compound purity were determined using Waters Micromass ZQ 4000, equipped with a Waters 2795 Separation Module, Waters 2996 Photodiode Array Detector, and a Waters 2424 ELSD. HPLC was performed on a Waters 2535 Separation Module with a Waters 2998 Photodiode Array Detector. using an

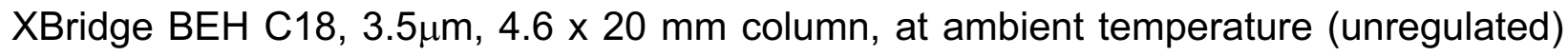
using a mobile phase of water-methanol containing a constant $0.05 \%$ formic acid. Highresolution mass spectra (HRMS) were obtained using a Finnigan LTQFT mass spectrometer by the mass spectrometry facility at the University of California, Berkeley. All compounds synthesized were $\geq 95 \%$ pure as determined by LC-MS, ${ }^{1} \mathrm{H},{ }^{13} \mathrm{C}$ and ${ }^{19} \mathrm{~F}$ NMR. 


\section{Synthetic procedures for (1"R, 3"R)-TRX-COBI and (1"S, 3"S)-TRX-COBI}

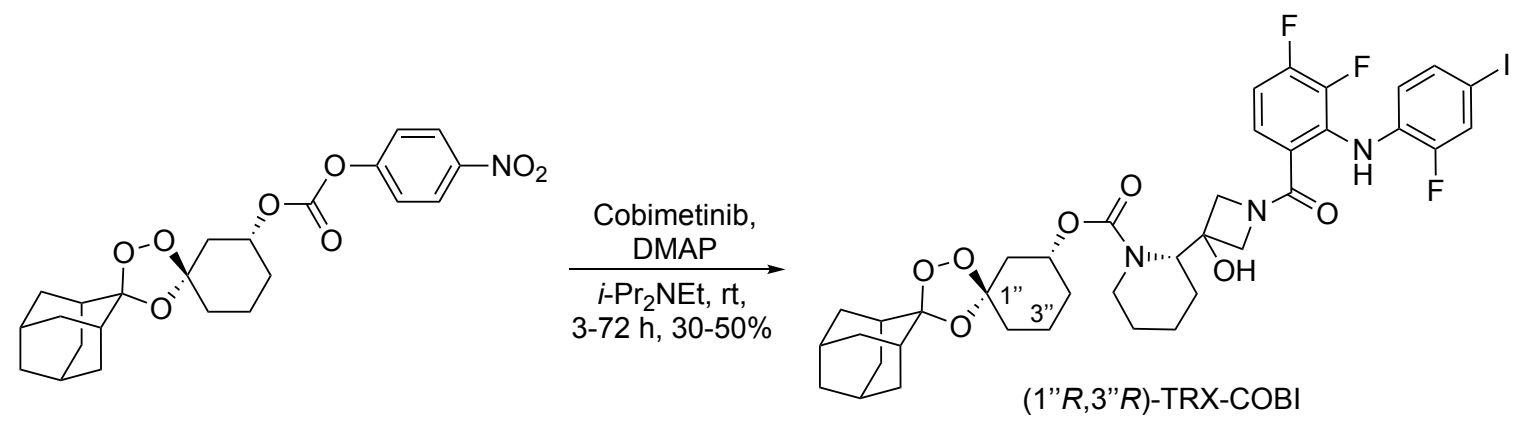

(1"R, 3"R)-dispiro[adamantane-2,3'-[1,2,4]trioxolane-5',1"-cyclohexan]-3"-yl (S)-2(1-(3,4-difluoro-2-((2-fluoro-4-iodophenyl)amino)benzoyl)-3-hydroxyazetidin-3-

\section{yl)piperidine-1-carboxylate}

To an oven-dried round bottom flask containing a magnetic stir bar under an $\operatorname{Ar}(\mathrm{g})$ atmosphere was added cobimetinib $(0.150 \mathrm{mg}, 0.28 \mathrm{mmol}, 1.0$ equiv) and ( 1 "R,3"R)dispiro[adamantane-2,3'-[1,2,4]trioxolane-5', 1"-cyclohexan]-3"-yl

(4-nitrophenyl) carbonate $(0.150 \mathrm{mg}, 0.34 \mathrm{mmol}, 1.2$ equiv) followed by dimethylformamide $(10 \mathrm{~mL}), \mathrm{N}, \mathrm{N}-$ diisopropylethylamine $(0.30 \mathrm{~mL}, 1.74 \mathrm{mmol}, 6.0$ equiv), and 4-dimethylaminopyridine $(0.038 \mathrm{~g}, 0.34 \mathrm{mmol}, 1.2$ equiv). Reactions were stirred at it for $3-72 \mathrm{~h}$ whilst monitoring reaction progress by LCMS. The reaction was then diluted with $\mathrm{DI}_{2} \mathrm{O}(100 \mathrm{~mL})$ and extracted with EtOAc $(1 \times 100 \mathrm{~mL})$. The organic layer was washed repeatedly with a satd. aq $\mathrm{NaHCO}_{3}$ solution until the aqueous layer was colorless and no longer yellow (indicating that most of the $p$-nitrophenol had been successfully removed from the organic layer). The organic layer was then dried $\left(\mathrm{Na}_{2} \mathrm{SO}_{4}\right)$, filtered and concentrated under reduced pressure to a viscous yellow oil. The crude material was then purified using flash column chromatography (40 g silica gel cartridge, initially using 0-50\% EtOAc-Hexanes and then switching to $0-15 \% \mathrm{MeOH}$ (containing $0.7 \mathrm{~N} \mathrm{NH}_{3}$ ) $/ \mathrm{CH}_{2} \mathrm{Cl}_{2}$, product eluted during $40 \%$ EtOAc-Hex, unreacted Cobimetinib eluted during $15 \% \mathrm{MeOH}$ (containing $0.7 \mathrm{~N}$ $\left.\mathrm{NH}_{3}\right) / \mathrm{CH}_{2} \mathrm{Cl}_{2}$ to yield the desired product (1"R,3" $R$ ) TRX-COBI (30-50\%) as a colorless solid (9:1 dr, trans:cis). ${ }^{1} \mathrm{H}$ NMR (1H NMR (400 MHz, CDCl3) $\delta 8.60(\mathrm{br} \mathrm{s}, 1 \mathrm{H}), 8.41(\mathrm{br}$ s, 1 H), 7.39 (dd, $J=10.4,1.6 \mathrm{~Hz}, 1 \mathrm{H}$ ), 7.32 (d, J = 8.5 Hz, 1 H), 7.15 (br s, $1 \mathrm{H}$ ), 6.82 (app q, $J=8.3 \mathrm{~Hz}, 1 \mathrm{H}$ ), $6.61(\mathrm{app} \mathrm{td}, J=8.5,5.4 \mathrm{~Hz}, 1 \mathrm{H}), 5.45(\mathrm{br} \mathrm{s}, 1 \mathrm{H}), 4.88$ (br s, 1 $\mathrm{H}$, minor diastereomer), 4.76 (app sept, $J=4.5 \mathrm{~Hz}, 1 \mathrm{H}), 4.11-4.25(\mathrm{~m}, 2 \mathrm{H}), 3.93-4.11$ 
(m, $3 \mathrm{H}), 3.22-3.44(\mathrm{~m}, 1 \mathrm{H}), 2.87(\mathrm{br} \mathrm{s}, 1 \mathrm{H}), 2.07-2.25(\mathrm{~m}, 1 \mathrm{H}), 1.86-2.02(\mathrm{~m}, 8 \mathrm{H})$, 1.72-1.85 (m, $7 \mathrm{H}), 1.46-1.65(\mathrm{~m}, 6 \mathrm{H}), 1.21-1.46(\mathrm{~m}, 3 \mathrm{H}) ;{ }^{13} \mathrm{C} \mathrm{NMR}\left(100 \mathrm{MHz}, \mathrm{CDCl}_{3}\right)$ $\delta$ 169.1, 155.4, 153.2 (br d, $J=249.7 \mathrm{~Hz}$ ), 152.8 (br d, $J=253.4 \mathrm{~Hz}$ ), 152.4 (br d, $J=$ 251.2 Hz), 143.5 (br d, J = 246.1 Hz), 132.9 (d, J = 3.7 Hz), $132.6(\mathrm{~d}, J=3.7 \mathrm{~Hz}), 130.8$ (d, $J=10.3 \mathrm{~Hz}$ ), 124.4, 124.2, 119.9, 119.6, 119.2, 111.8, 111.8 (minor diastereomer), 109.1 (br d, $J=17.5 \mathrm{~Hz}$ ), 108.5, 108.3, 81.6 (d, $J=7.3 \mathrm{~Hz}$ ), 77.3, 72.0, 70.9 (br s), 65.2, 64.9, 60.3, 60.1, 48.0 (br s), 39.6, 36.7, 36.4, 36.3, 34.9, 34.7, 34.0, 33.9 (minor diastereomer), 30.5, 30.2 (minor diastereomer), 29.7, 26.9, 26.4, 25.4, 25.0 (br s), 24.1 (br s), 19.5, 19.4 (minor diastereomer), several minor diastereomer peaks overlapping or not observed; ${ }^{19} \mathrm{~F}$ NMR (376 MHz, $\left.\mathrm{CDCl}_{3}\right) \delta$-126.9, -127.0, -127.1 (br s), -131.3 (br s), 141.4 (br s); LRMS (ESI): $\mathrm{m} / \mathrm{z}[\mathrm{M}+\mathrm{Na}]^{+}$calcd for $\mathrm{C}_{38} \mathrm{H}_{43} \mathrm{~F}_{3} \mathrm{IN}_{3} \mathrm{O}_{7} \mathrm{Na}: 860.20$, found: 860.15 , retention time $=13.1$ mins (diode array), HRMS $(E S I) \mathrm{m} / \mathrm{z}[\mathrm{M}+\mathrm{Na}]^{+}$calcd for $\mathrm{C}_{38} \mathrm{H}_{43} \mathrm{~F}_{3} \mathrm{IN}_{3} \mathrm{O}_{7} \mathrm{Na}$ : 860.1995, found: 860.1975. 


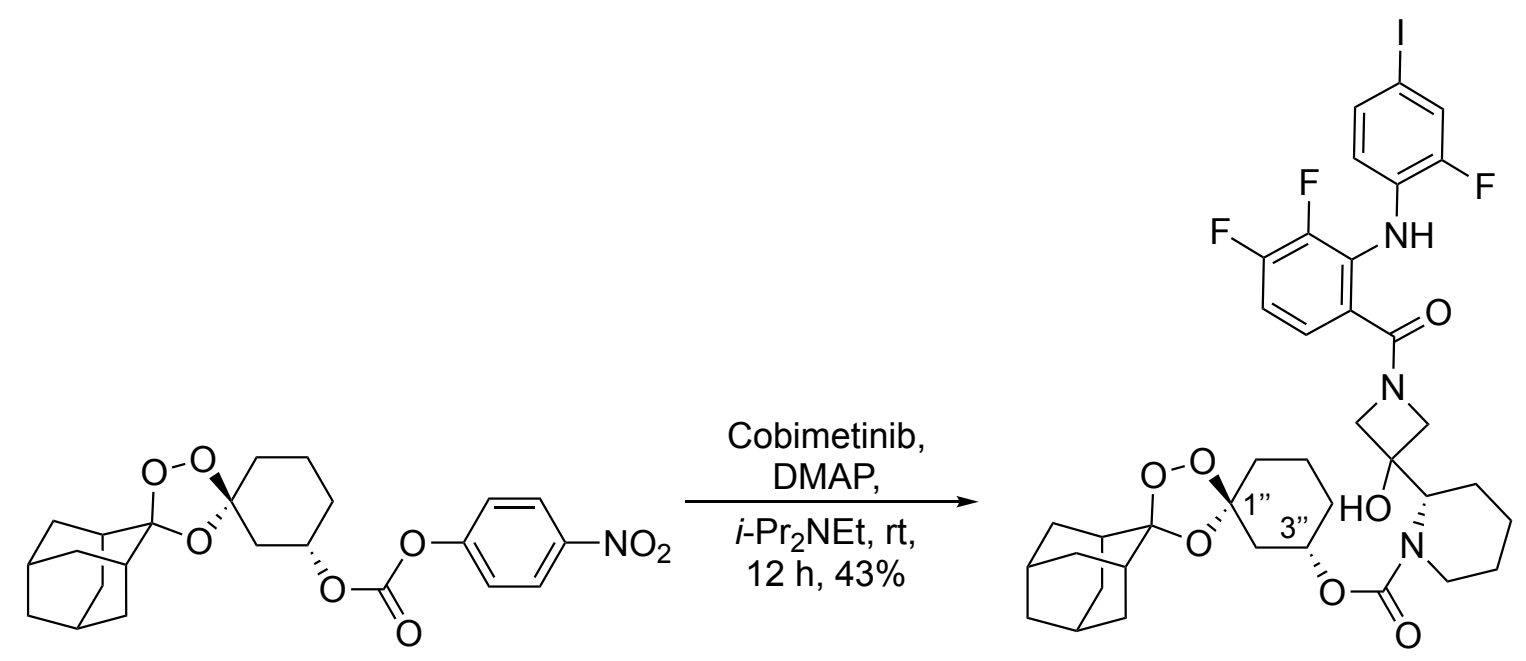

(1"S,3"S)-TRX-COBI

(1'"S,3"S)-dispiro[adamantane-2,3'-[1,2,4]trioxolane-5',1"-cyclohexan]-3"-yl (S)-2(1-(3,4-difluoro-2-((2-fluoro-4-iodophenyl)amino)benzoyl)-3-hydroxyazetidin-3-

\section{yl)piperidine-1-carboxylate}

To a $20 \mathrm{~mL}$ scintillation vial containing a magnetic stir bar under an $\operatorname{Ar}(\mathrm{g})$ atmosphere was added cobimetinib (238 mg, $0.45 \mathrm{mmol}, 2.50$ equiv.), (1"S, 3"S)-dispiro[adamantane-2,3'[1,2,4]trioxolane-5',1"-cyclohexan]-3"-yl (4-nitrophenyl)carbonate ( 80 mg, 0.18 mmol, 1.0 equiv), N,N-dimethylformamide (1.60 mL), N,N-diisopropylethylamine (78 uL, $0.45 \mathrm{mmol}$, 2.50 equiv), and 4-dimethylaminopyridine ( $28.6 \mathrm{mg}, 0.23 \mathrm{mmol}, 1.3$ equiv). The reaction was stirred at it for $12 \mathrm{~h}$ and monitored by TLC and LC/MS. The reaction was then diluted with satd. aq. $\mathrm{NaHCO}_{3}(15 \mathrm{~mL})$ and EtOAc $(15 \mathrm{~mL})$ and the layers were separated. The aqueous layer was further extracted with EtOAc $(3 \times 15 \mathrm{~mL})$ and the combined organic phases were washed repeatedly with satd. aq $\mathrm{NaHCO}_{3}$ until the aqueous layer was colorless and no longer yellow (indicating that most of the $p$-nitrophenol had been successfully removed from the organic layer). The organic phase was then dried $\left(\mathrm{MgSO}_{4}\right)$, filtered, and concentrated under reduced pressure to afford a crude viscous yellow oil. The crude material was purified by preparative HPLC $(40-100 \% \mathrm{MeOH}$-water $+0.05 \%$ formic acid) and the product-bearing fractions were combined, concentrated and lyophilized to give (1"S,3"S)-TRX-COBI $(65.2 \mathrm{mg}, 0.078 \mathrm{mmol}, 43 \%)$ as a colorless lyophilized solid (9:1 dr, trans:cis). ${ }^{1} \mathrm{H}$ NMR $\left(400 \mathrm{MHz}, \mathrm{CDCl}_{3}\right) \delta 8.57$ (br s, $\left.1 \mathrm{H}\right), 8.43(\mathrm{br}$ s, $1 \mathrm{H}), 7.41(\mathrm{dd}, J=10.4,1.8 \mathrm{~Hz}, 1 \mathrm{H}), 7.34(\mathrm{br} \mathrm{d}, J=8.8 \mathrm{~Hz}, 1 \mathrm{H}), 7.16-7.17(\mathrm{~m}, 1 \mathrm{H})$, 
$6.83(\mathrm{br} \mathrm{d}, J=7.1 \mathrm{~Hz}), 6.62(\mathrm{td}, J=8.6,5.4 \mathrm{~Hz}), 5.2-5.8(\mathrm{~m}, 1 \mathrm{H}), 4.85-4.93(\mathrm{~m}, 1 \mathrm{H}$, minor diastereomer), $4.74(\mathrm{br} \mathrm{s}, 1 \mathrm{H}), 4.09-4.29(\mathrm{~m}, 2 \mathrm{H}), 3.91-4.09(\mathrm{~m}, 3 \mathrm{H}), 3.40(\mathrm{br} \mathrm{s}, 1 \mathrm{H})$, 3.27 (br s, 1H), 2.92 (br s, 1H), $2.24(\mathrm{br} \mathrm{d}, J=12.2 \mathrm{~Hz}, 1 \mathrm{H}), 1.88-2.03(\mathrm{~m}, 8 \mathrm{H}), 1.74-$ $1.88(\mathrm{~m}, 7 \mathrm{H}), 1.56-1.67(\mathrm{~m}, 5 \mathrm{H}), 1.43-1.56(\mathrm{~m}, 3 \mathrm{H}), 1.23-1.42(\mathrm{~m}, 2 \mathrm{H}) ;{ }^{13} \mathrm{C}$ NMR $(100$ $\left.\mathrm{MHz} \mathrm{CDCl}_{3}\right) \delta 169.1,155.4,153.7$ (br d, $J=249.7$ ), 152.7 (br d, $\left.J=252.7\right), 152.6$ (br d, $J=251.9), 143.5$ (br d, $J=238.1 \mathrm{~Hz}), 132.9$ (br d, $J=2.9 \mathrm{~Hz}), 132.4-132.7(\mathrm{~m}), 132.1-$ $132.4(\mathrm{~m}), 130.8$ (br d, $J=12.4 \mathrm{~Hz}$ ), 124.4, 124.2, 119.8, 119.6, 119.3, 111.8, 111.8 (minor diastereomer), 109.2 ( $\mathrm{br} \mathrm{d}, J=18.3 \mathrm{~Hz}$ ), 108.6, 81.6 (d, $J=5.9 \mathrm{~Hz}), 77.2,72.1$, 72.0 (minor diastereomer), 70.9 (br s), 65.1, 64.9 (br s), 60.3, 60.1, 47.8 (br s), 40.0, 39.6 (minor diastereomer), 36.7, 36.3, 36.3, 34.8, 34.8, 33.9, 33.8 (minor diastereomer), 30.6, 30.2 (minor diastereomer), 26.9, 26.4, 25.4, 25.0, 24.1 (br s), 19.6, several minor diastereomer peaks overlapping or not observed; ${ }^{19} \mathrm{~F}$ NMR $\left(376 \mathrm{MHz}, \mathrm{CDCl}_{3}\right) \delta-126.9$, 127.1, -131.3 (dd, $J=7.5,11.3 \mathrm{~Hz}$ ), -141.4 (d, $J=19.1 \mathrm{~Hz}$ ); LRMS (ESI): m/z [M+Na] ${ }^{+}$ calcd for $\mathrm{C}_{38} \mathrm{H}_{43} \mathrm{~F}_{3} \mathrm{IN}_{3} \mathrm{O}_{7} \mathrm{Na:} 860.20$, found: 860.22 , retention time = 13.58 mins (ELSD); HRMS (ESI) $\mathrm{m} / \mathrm{z}[\mathrm{M}+\mathrm{Na}]^{+}$calcd for $\mathrm{C}_{38} \mathrm{H}_{43} \mathrm{~F}_{3} \mathrm{IN}_{3} \mathrm{O}_{7} \mathrm{Na}[\mathrm{M}+\mathrm{Na}]^{+}:$860.1995, found: 860.1979. 
${ }^{1} \mathrm{H},{ }^{13} \mathrm{C}$ NMR, ${ }^{19} \mathrm{~F}, \mathrm{LCMS}$ and HRMS data for $(1 " R, 3 " R)$ TRX-COBI
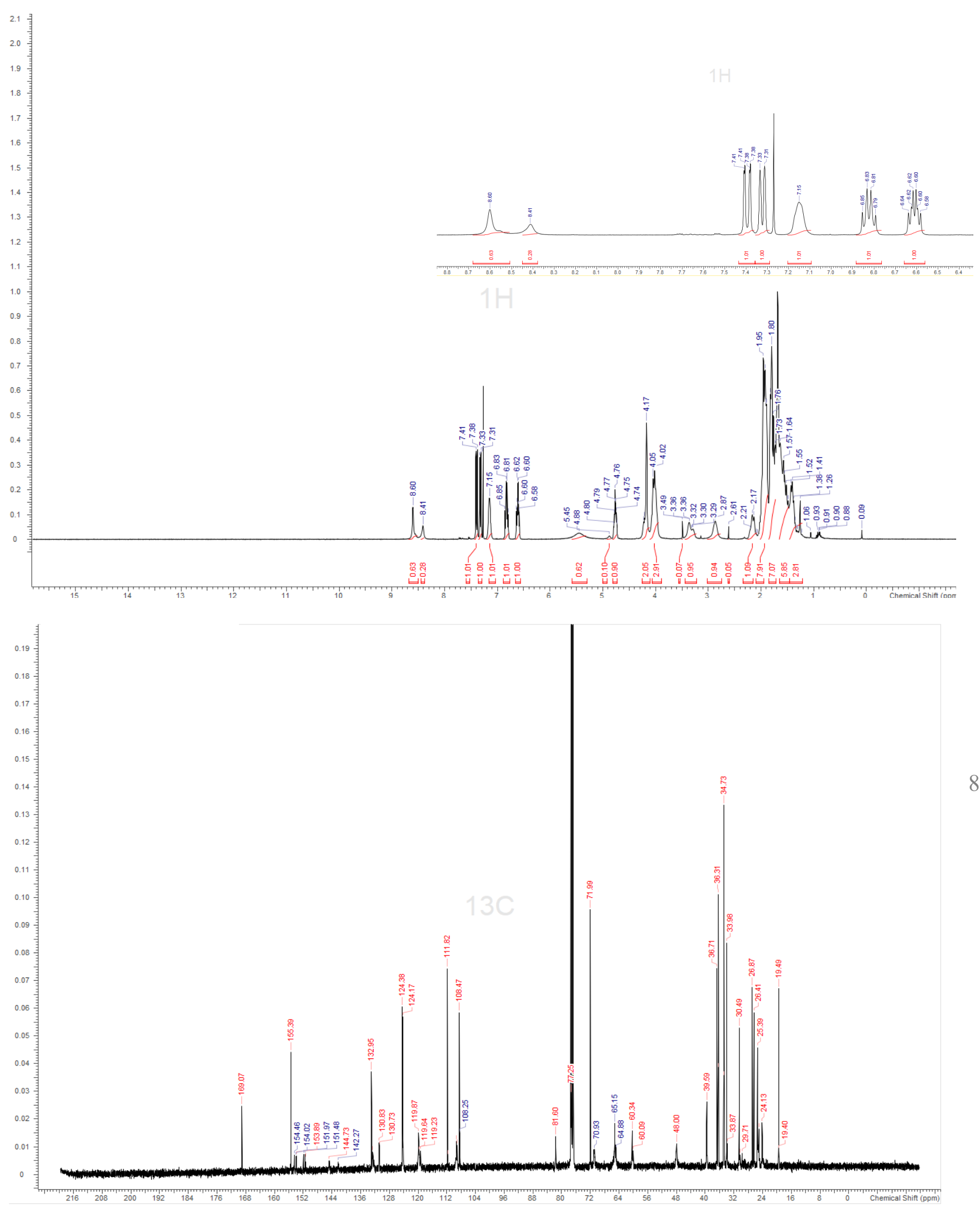
bioRxiv preprint doi: https://doi.org/10.1101/2020.05.12.088971; this version posted May 14, 2020. The copyright holder for this preprint (which was not certified by peer review) is the author/funder. All rights reserved. No reuse allowed without permission.
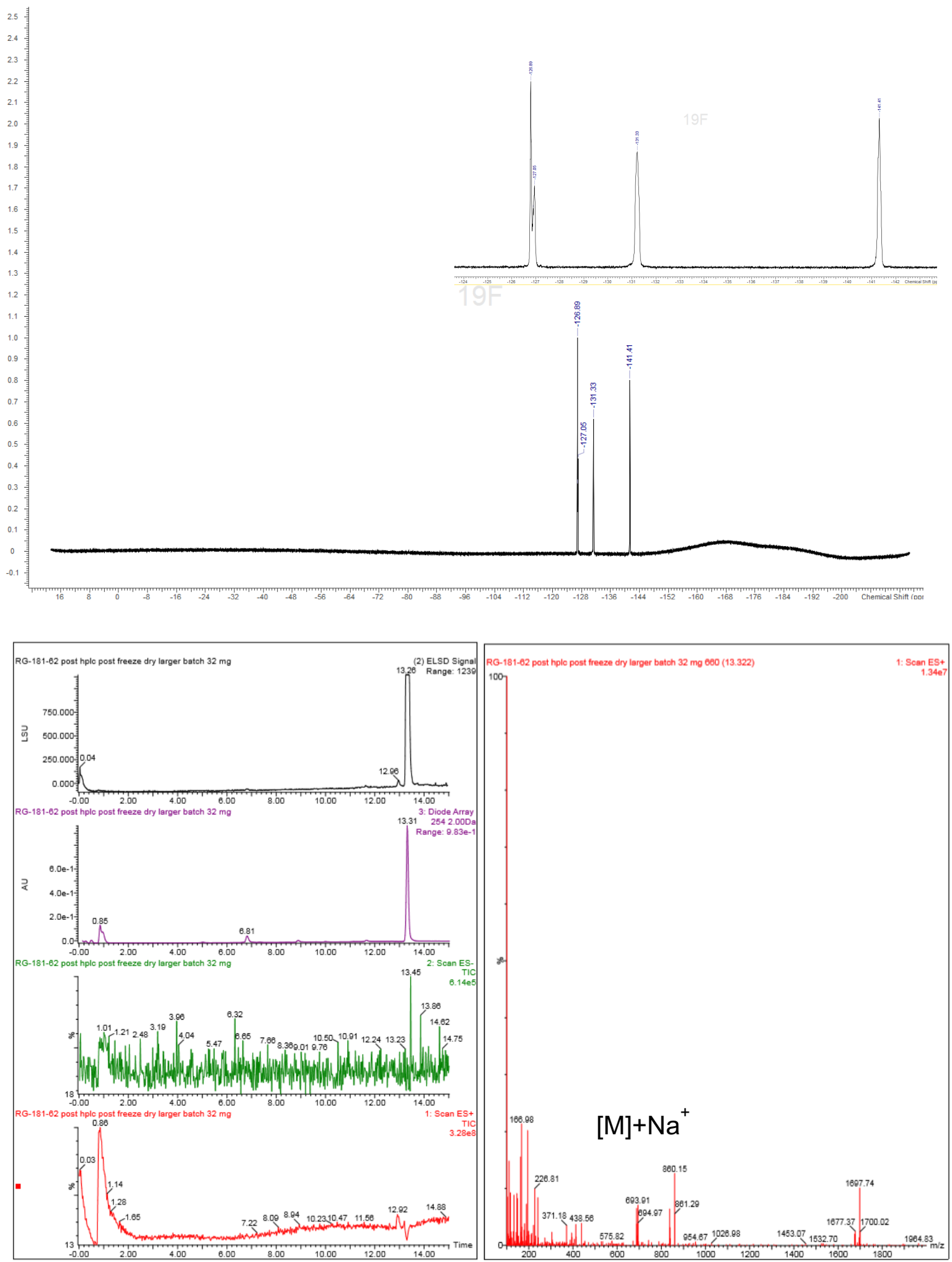
bioRxiv preprint doi: https://doi.org/10.1101/2020.05.12.088971; this version posted May 14,2020 . The copyright holder for this preprint (which was not certified by peer review) is the author/funder. All rights reserved. No reuse allowed without permission.

C:IXCaliburL...LFT19604

LFT19604 \#1-57 RT: 0.01-0.99 AV: 57 NL: 2.33E5

T: FTMS + p ESI Full ms [620.00-1200.00]

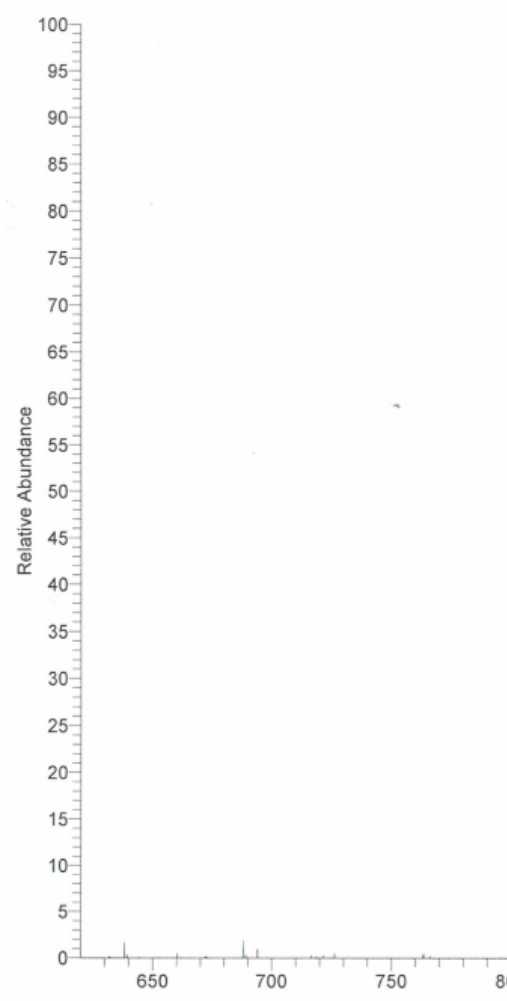

$7 / 29 / 2019$ 1:02:04 PM

Gonciarz/Renslo, SMDC1047678 Lot\#1

860.1975

$[\mathrm{M}]+\mathrm{Na}^{+}$

$\underset{838.2169}{[\mathrm{M}]+\mathrm{H}^{+}}[\mathrm{M}]+\mathrm{K}^{+}$

$\underset{z=1}{876.1723} 935.2043$
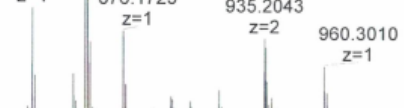
bioRxiv preprint dol: https://doi.org/10.1101/2020.05.12.088971; this version posted May 14, 2020. The copyright holder for this preprint (which was not certified by peer review) is the author/funder. All rights reserved. No reuse allowed without permission.

${ }^{1} \mathrm{H},{ }^{13} \mathrm{C}$ NMR, ${ }^{19} \mathrm{~F}, \mathrm{LCMS}$, and HRMS data for (1"S, 3"S) TRX-COBI
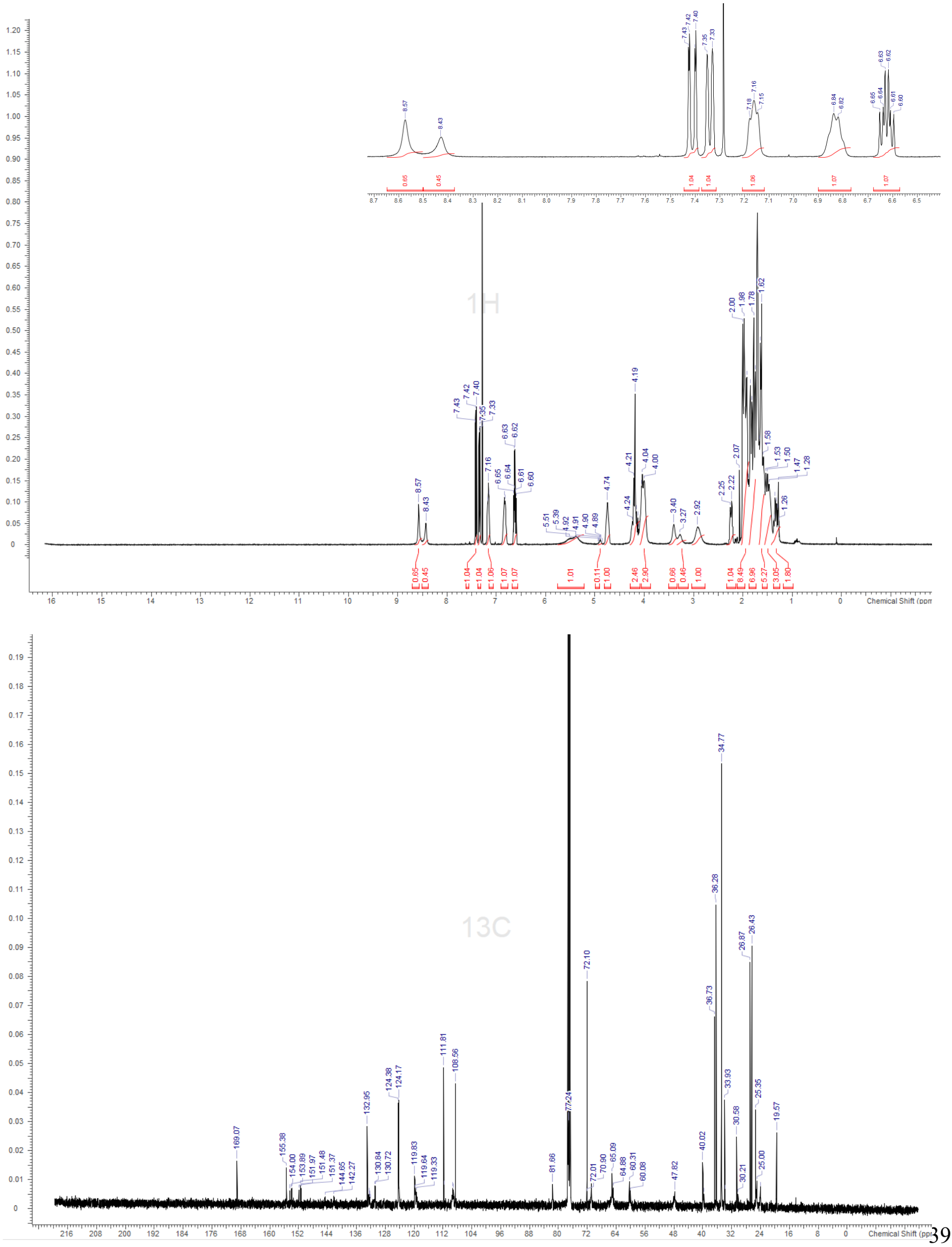

11 
bioRxiv preprint doi: https://doi.org/10.1101/2020.05.12.088971; this version posted May 14, 2020. The copyright holder for this preprint (which was not certified by peer review) is the author/funder. All rights reserved. No reuse allowed without permission.
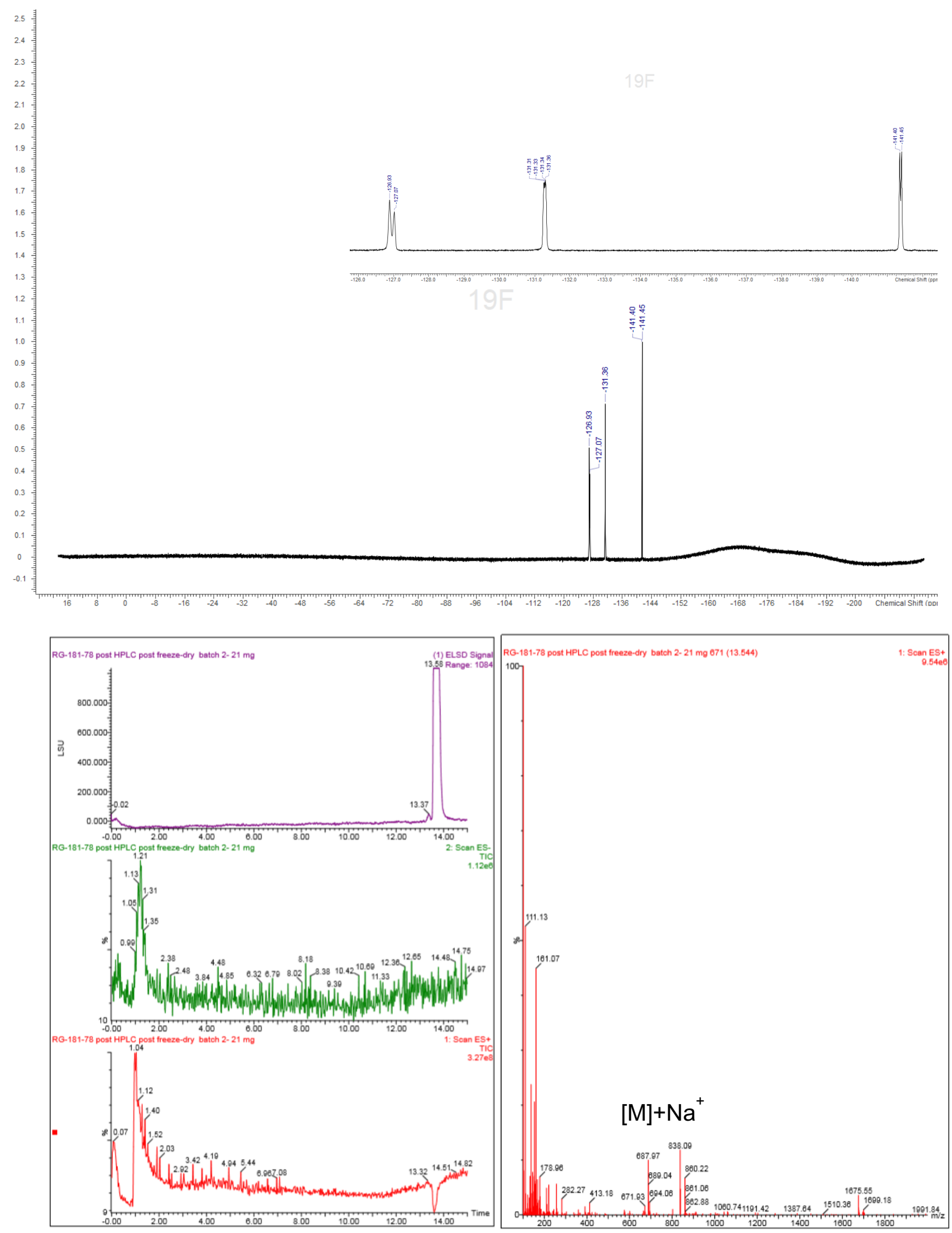
bioRxiv preprint doi: https://doi.org/10.1101/2020.05.12.088971; this version posted May 14,2020 . The copyright holder for this preprint (which was not certified by peer review) is the author/funder. All rights reserved. No reuse allowed without permission.

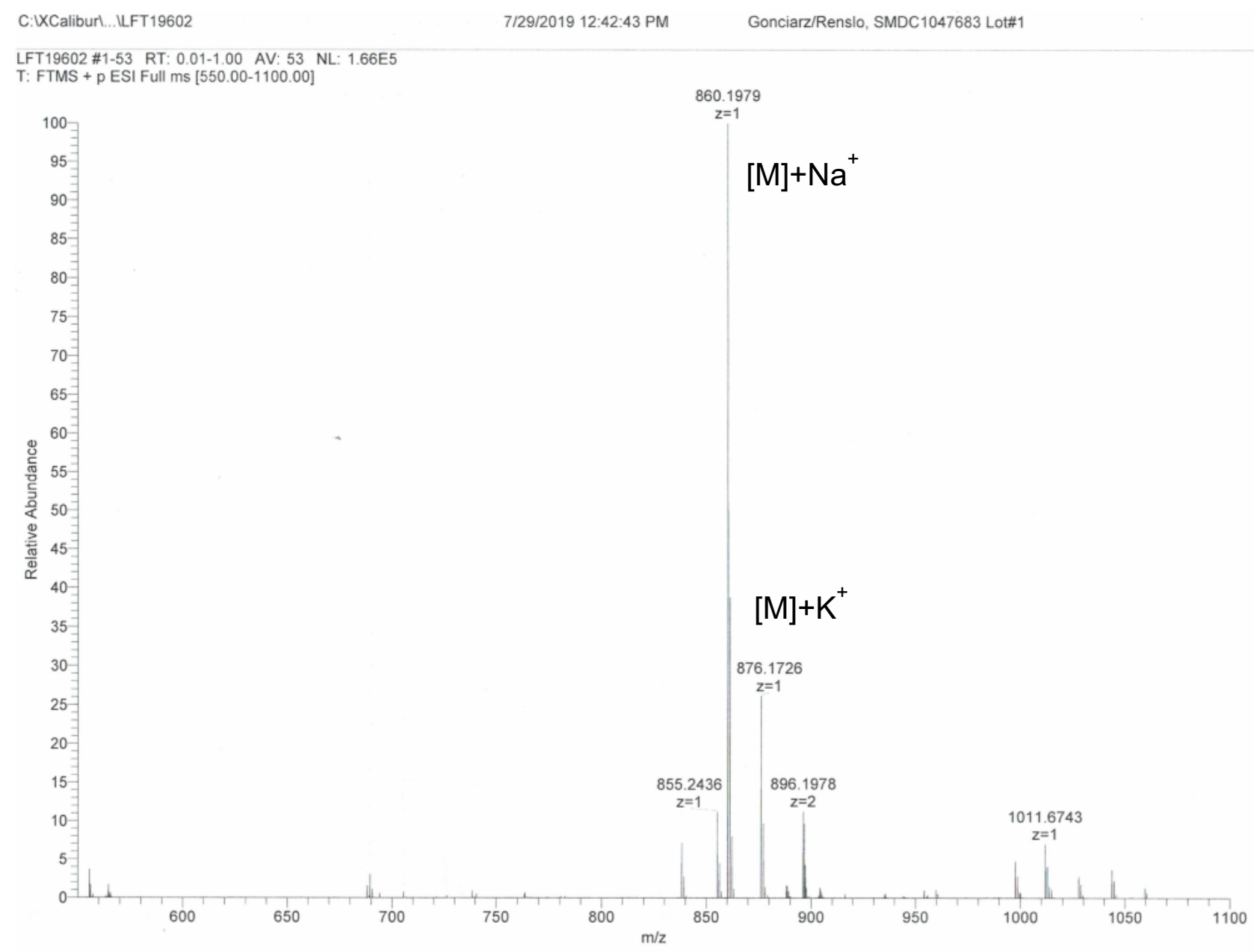




\section{Supplementary figure legends}

\section{Figure S1}

(A) ${ }^{18} \mathrm{~F}$-TRX uptake of mice bearing xenografts with wild type or mutant KRAS. Error bars represent mean \pm SEM, $n=3$ mice/group and analyzed by two sample t test. ${ }^{*} p<0.05$.

(B) Proliferation curve of $L S L-K R A S^{G 12 D}$ fibroblasts with or without AdenoCre treatment.

(C) West blot for p21 of $L S L-K R A S^{G 12 D}$ fibroblasts before and after the treatment with AdenoCre at $24 \mathrm{~h}, 48 \mathrm{~h}$ and $72 \mathrm{~h}$.

(D) Quantative PCR analysis of STEAP3 and Ferroportin expression in indicated cells.

\section{Figure S2}

(A) Representative images of HE (40X) show the epidermal layer of mouse tail skin after the treatment with vehicle and Binimetinib after 20days.

(B) Quantification of intracellular Fe2+ levels in MiaPaca2 and Capan-1 cells with STEAP3 knockdown and iron chelator DFO treatment.

(C-D) Phospho-ERK/total ERK levels in t MiaPaca2 and Capan-1 cells with STEAP3 knockdown and prior $24 \mathrm{~h}$ of iron chelator DFO treatment. Cells were treated with the indicated concentration of TRX-COBI for $2 \mathrm{~h}$ before lysis. Error bars indicate $\pm S D$.

\section{Figure S3}

(A) IHC staining with phosphorylated ERK of tail skin (10X) after the treatment of vehicle, the equimolar dose of $\mathrm{COBI}$ and TRX-COBI for $8 \mathrm{~h}$, corresponding to Figure $5 \mathrm{C}$.

(B) Mouse body weight changes normalized to the baseline after the treatment by the addition of indicated doses of $\mathrm{COBI}$ or TRX-COBI to SHP009. Error bars represent mean \pm SEM, $\mathrm{n}=6 \mathrm{mice} /$ group and analyzed by two-sample t-test. ${ }^{* * *} \mathrm{p}<0.001$. 


\section{References:}

Adjei, A.A., Cohen, R.B., Franklin, W., Morris, C., Wilson, D., Molina, J.R., Hanson, L.J., Gore, L., Chow, L., Leong, S., et al. (2008). Phase I pharmacokinetic and pharmacodynamic study of the oral, small-molecule mitogen-activated protein kinase kinase 1/2 inhibitor AZD6244 (ARRY142886) in patients with advanced cancers. J Clin Oncol 26, 2139-2146.

Aguirre, A.J., Nowak, J.A., Camarda, N.D., Moffitt, R.A., Ghazani, A.A., Hazar-Rethinam, M., Raghavan, S., Kim, J., Brais, L.K., Ragon, D., et al. (2018). Real-time genomic characterization of advanced pancreatic cancer to enable precision medicine. Cancer Discov.

Ansari, M.T., Saify, Z.S., Sultana, N., Ahmad, I., Saeed-Ul-Hassan, S., Tariq, I., and Khanum, M. (2013). Malaria and artemisinin derivatives: an updated review. Mini Rev Med Chem 13, 18791902.

Balagula, Y., Barth Huston, K., Busam, K.J., Lacouture, M.E., Chapman, P.B., and Myskowski, P.L. (2011). Dermatologic side effects associated with the MEK 1/2 inhibitor selumetinib (AZD6244, ARRY-142886). Invest New Drugs 29, 1114-1121.

Behr, S.C., Villanueva-Meyer, J.E., Li, Y., Wang, Y.H., Wei, J., Moroz, A., Lee, J.K., Hsiao, J.C., Gao, K.T., Ma, W., et al. (2018). Targeting iron metabolism in high-grade glioma with 68Ga-citrate PET/MR. JCI Insight 3.

Bersuker, K., Hendricks, J.M., Li, Z., Magtanong, L., Ford, B., Tang, P.H., Roberts, M.A., Tong, B., Maimone, T.J., Zoncu, R., et al. (2019). The CoQ oxidoreductase FSP1 acts parallel to GPX4 to inhibit ferroptosis. Nature 575, 688-692.

Burgess, M.R., Hwang, E., Mroue, R., Bielski, C.M., Wandler, A.M., Huang, B.J., Firestone, A.J., Young, A., Lacap, J.A., Crocker, L., et al. (2017). KRAS Allelic Imbalance Enhances Fitness and Modulates MAP Kinase Dependence in Cancer. Cell 168, 817-829 e815.

Buss, J.L., Torti, F.M., and Torti, S.V. (2003). The role of iron chelation in cancer therapy. Curr Med Chem 10, 1021-1034.

Choo, E.F., Belvin, M., Boggs, J., Deng, Y., Hoeflich, K.P., Ly, J., Merchant, M., Orr, C., Plise, E., Robarge, K., et al. (2012). Preclinical disposition of GDC-0973 and prospective and retrospective analysis of human dose and efficacy predictions. Drug Metab Dispos 40, 919-927.

Collisson, E.A., Trejo, C.L., Silva, J.M., Gu, S., Korkola, J.E., Heiser, L.M., Charles, R.P., Rabinovich, B.A., Hann, B., Dankort, D., et al. (2012). A Central Role for RAF->MEK->ERK Signaling in the Genesis of Pancreatic Ductal Adenocarcinoma. Cancer Discovery.

Dixon, S.J., Lemberg, K.M., Lamprecht, M.R., Skouta, R., Zaitsev, E.M., Gleason, C.E., Patel, D.N., Bauer, A.J., Cantley, A.M., Yang, W.S., et al. (2012). Ferroptosis: an iron-dependent form of nonapoptotic cell death. Cell 149, 1060-1072.

Dixon, S.J., and Stockwell, B.R. (2014). The role of iron and reactive oxygen species in cell death. Nat Chem Biol 10, 9-17.

Dizdaroglu, M., and Jaruga, P. (2012). Mechanisms of free radical-induced damage to DNA. Free Radic Res 46, 382-419.

Doll, S., Freitas, F.P., Shah, R., Aldrovandi, M., da Silva, M.C., Ingold, I., Grocin, A.G., Xavier da Silva, T.N., Panzilius, E., Scheel, C.H., et al. (2019). FSP1 is a glutathione-independent ferroptosis suppressor. Nature 575, 693-698.

Eshelman, K., Yao, H., Punchi Hewage, A.N.D., Deay, J.J., Chandler, J.R., and Rivera, M. (2017). Inhibiting the BfrB:Bfd interaction in Pseudomonas aeruginosa causes irreversible iron 
accumulation in bacterioferritin and iron deficiency in the bacterial cytosol. Metallomics 9, 646659.

Fedele, C., Ran, H., Diskin, B., Wei, W., Jen, J., Geer, M.J., Araki, K., Ozerdem, U., Simeone, D.M., Miller, G., et al. (2018). SHP2 Inhibition Prevents Adaptive Resistance to MEK Inhibitors in Multiple Cancer Models. Cancer Discov 8, 1237-1249.

Fontaine, S.D., DiPasquale, A.G., and Renslo, A.R. (2014). Efficient and stereocontrolled synthesis of 1,2,4-trioxolanes useful for ferrous iron-dependent drug delivery. Org Lett 16, 5776-5779.

Forcina, G.C., and Dixon, S.J. (2019). GPX4 at the Crossroads of Lipid Homeostasis and Ferroptosis. Proteomics 19, e1800311.

Han, M., Xu, R., Wang, S., Yang, N., Ni, S., Zhang, Q., Xu, Y., Zhang, X., Zhang, C., Wei, Y., et al. (2018). Six-Transmembrane Epithelial Antigen of Prostate 3 Predicts Poor Prognosis and Promotes Glioblastoma Growth and Invasion. Neoplasia 20, 543-554.

Hangauer, M.J., Viswanathan, V.S., Ryan, M.J., Bole, D., Eaton, J.K., Matov, A., Galeas, J., Dhruv, H.D., Berens, M.E., Schreiber, S.L., et al. (2017). Drug-tolerant persister cancer cells are vulnerable to GPX4 inhibition. Nature 551, 247-250.

Hensley, C.T., Faubert, B., Yuan, Q., Lev-Cohain, N., Jin, E., Kim, J., Jiang, L., Ko, B., Skelton, R., Loudat, L., et al. (2016). Metabolic Heterogeneity in Human Lung Tumors. Cell 164, 681-694.

Hirayama, T., Inden, M., Tsuboi, H., Niwa, M., Uchida, Y., Naka, Y., Hozumi, I., and Nagasawa, H. (2019). A Golgi-targeting fluorescent probe for labile Fe(ii) to reveal an abnormal cellular iron distribution induced by dysfunction of VPS35. Chem Sci 10, 1514-1521.

Infante, J.R., Fecher, L.A., Falchook, G.S., Nallapareddy, S., Gordon, M.S., Becerra, C., DeMarini, D.J., Cox, D.S., Xu, Y., Morris, S.R., et al. (2012). Safety, pharmacokinetic, pharmacodynamic, and efficacy data for the oral MEK inhibitor trametinib: a phase 1 dose-escalation trial. Lancet Oncol $13,773-781$.

Inoue, S., and Kawanishi, S. (1987). Hydroxyl radical production and human DNA damage induced by ferric nitrilotriacetate and hydrogen peroxide. Cancer Res 47, 6522-6527.

Jackson, E.L., Willis, N., Mercer, K., Bronson, R.T., Crowley, D., Montoya, R., Jacks, T., and Tuveson, D.A. (2001). Analysis of lung tumor initiation and progression using conditional expression of oncogenic K-ras. Genes \& development 15, 3243-3248.

Karreth, F.A., Frese, K.K., Denicola, G.M., Baccarini, M., and Tuveson, D.A. (2011). C-Raf is required for the initiation of lung cancer by K-Ras. Cancer Discovery 1, 128-136.

Ko, A.H., Bekaii-Saab, T., Van Ziffle, J., Mirzoeva, O.M., Joseph, N.M., Talasaz, A., Kuhn, P., Tempero, M.A., Collisson, E.A., Kelley, R.K., et al. (2016). A Multicenter, Open-Label Phase II Clinical Trial of Combined MEK plus EGFR Inhibition for Chemotherapy-Refractory Advanced Pancreatic Adenocarcinoma. Clin Cancer Res 22, 61-68.

Larson, S.M., Rasey, J.S., Allen, D.R., Nelson, N.J., Grunbaum, Z., Harp, G.D., and Williams, D.L. (1980). Common pathway for tumor cell uptake of gallium-67 and iron-59 via a transferrin receptor. J Natl Cancer Inst 64, 41-53.

Liu, H., Schreiber, S.L., and Stockwell, B.R. (2018). Targeting Dependency on the GPX4 Lipid Peroxide Repair Pathway for Cancer Therapy. Biochemistry 57, 2059-2060.

Mahajan, S.S., Gut, J., Rosenthal, P.J., and Renslo, A.R. (2012). Ferrous iron-dependent delivery of therapeutic agents to the malaria parasite. Future Med Chem 4, 2241-2249. 
Miller, L.D., Coffman, L.G., Chou, J.W., Black, M.A., Bergh, J., D'Agostino, R., Jr., Torti, S.V., and Torti, F.M. (2011). An iron regulatory gene signature predicts outcome in breast cancer. Cancer Res 71, 6728-6737.

Muir, R.K., Zhao, N., Wei, J., Wang, Y.H., Moroz, A., Huang, Y., Chen, Y.C., Sriram, R., Kurhanewicz, J., Ruggero, D., et al. (2019). Measuring Dynamic Changes in the Labile Iron Pool in Vivo with a Reactivity-Based Probe for Positron Emission Tomography. ACS Cent Sci 5, 727-736.

O'Neill, P.M., and Posner, G.H. (2004). A medicinal chemistry perspective on artemisinin and related endoperoxides. J Med Chem 47, 2945-2964.

Papke, B., and Der, C.J. (2017). Drugging RAS: Know the enemy. Science 355, 1158-1163.

Perera, R.M., and Bardeesy, N. (2015). Pancreatic Cancer Metabolism: Breaking It Down to Build It Back Up. Cancer Discov 5, 1247-1261.

Pinnix, Z.K., Miller, L.D., Wang, W., D'Agostino, R., Jr., Kute, T., Willingham, M.C., Hatcher, H., Tesfay, L., Sui, G., Di, X., et al. (2010). Ferroportin and iron regulation in breast cancer progression and prognosis. Sci Transl Med 2, 43 ra56.

Ruess, D.A., Heynen, G.J., Ciecielski, K.J., Ai, J., Berninger, A., Kabacaoglu, D., Gorgulu, K., Dantes, Z., Wormann, S.M., Diakopoulos, K.N., et al. (2018). Mutant KRAS-driven cancers depend on PTPN11/SHP2 phosphatase. Nat Med 24, 954-960.

Saunders, I.M., Goodman, A.M., and Kurzrock, R. (2020). Real-World Toxicity Experience with BRAF/MEK Inhibitors in Patients with Erdheim-Chester Disease. The oncologist 25, e386-e390.

Scholl, F.A., Dumesic, P.A., Barragan, D.I., Harada, K., Charron, J., and Khavari, P.A. (2009). Selective role for Mek1 but not Mek2 in the induction of epidermal neoplasia. Cancer Res 69, 3772-3778.

Schonberg, D.L., Miller, T.E., Wu, Q., Flavahan, W.A., Das, N.K., Hale, J.S., Hubert, C.G., Mack, S.C., Jarrar, A.M., Karl, R.T., et al. (2015). Preferential Iron Trafficking Characterizes Glioblastoma Stem-like Cells. Cancer Cell 28, 441-455.

Serrano, M., Lin, A.W., McCurrach, M.E., Beach, D., and Lowe, S.W. (1997). Oncogenic ras provokes premature cell senescence associated with accumulation of p53 and p16INK4a. Cell 88, 593-602.

Siegel, R.L., Miller, K.D., and Jemal, A. (2018). Cancer statistics, 2018. CA Cancer J Clin 68, 7-30. Spangler, B., Morgan, C.W., Fontaine, S.D., Vander Wal, M.N., Chang, C.J., Wells, J.A., and Renslo, A.R. (2016). A reactivity-based probe of the intracellular labile ferrous iron pool. Nat Chem Biol $12,680-685$.

Stephen, A.G., Esposito, D., Bagni, R.K., and McCormick, F. (2014). Dragging ras back in the ring. Cancer Cell 25, 272-281.

Stockwell, B.R., Friedmann Angeli, J.P., Bayir, H., Bush, A.I., Conrad, M., Dixon, S.J., Fulda, S., Gascon, S., Hatzios, S.K., Kagan, V.E., et al. (2017). Ferroptosis: A Regulated Cell Death Nexus Linking Metabolism, Redox Biology, and Disease. Cell 171, 273-285.

Tesfay, L., Clausen, K.A., Kim, J.W., Hegde, P., Wang, X., Miller, L.D., Deng, Z., Blanchette, N., Arvedson, T., Miranti, C.K., et al. (2015). Hepcidin regulation in prostate and its disruption in prostate cancer. Cancer Res 75, 2254-2263.

Torti, S.V., and Torti, F.M. (2013a). Cellular iron metabolism in prognosis and therapy of breast cancer. Crit Rev Oncog 18, 435-448.

Torti, S.V., and Torti, F.M. (2013b). Iron and cancer: more ore to be mined. Nat Rev Cancer 13, 342-355. 
Weber, R.A., Yen, F.S., Nicholson, S.P.V., Alwaseem, H., Bayraktar, E.C., Alam, M., Timson, R.C., La, K., Abu-Remaileh, M., Molina, H., et al. (2020). Maintaining Iron Homeostasis Is the Key Role of Lysosomal Acidity for Cell Proliferation. Mol Cell 77, 645-655 e647.

Ying, H., Kimmelman, A.C., Lyssiotis, C.A., Hua, S., Chu, G.C., Fletcher-Sananikone, E., Locasale, J.W., Son, J., Zhang, H., Coloff, J.L., et al. (2012). Oncogenic Kras maintains pancreatic tumors through regulation of anabolic glucose metabolism. Cell 149, 656-670.

Zhao, Y., and Adjei, A.A. (2014). The clinical development of MEK inhibitors. Nat Rev Clin Oncol $11,385-400$. 